\title{
The contrasting human gut microbiota in early and late life and implications for host health and disease
}

\author{
O. Skillington ${ }^{\mathrm{a}, \mathrm{b}}$, S. Mills ${ }^{\mathrm{a}}$, A. Gupta ${ }^{\mathrm{c}}$, E.A. Mayer ${ }^{\mathrm{d}}$, C.I.R. Gill ${ }^{\mathrm{e}}$, D. Del Rio ${ }^{\mathrm{f}}$, K.J. O’Riordan ${ }^{\mathrm{a}}$, \\ J.F. Cryan ${ }^{\mathrm{a}}$, R.P. Ross ${ }^{\mathrm{a}}$ and C. Stanton ${ }^{\mathrm{a}, \mathrm{b}, *}$ \\ ${ }^{a}$ APC Microbiome Ireland, University College Cork, Cork, Ireland \\ ${ }^{\mathrm{b}}$ Vistamilk \& Teagasc Food Research Centre, Fermoy, Co. Cork, Ireland \\ ${ }^{\mathrm{c}}$ Oppenheimer Center for Neurobiology of Stress and Resilience; Vatche and Tamar Manoukian Division of \\ Digestive Diseases; David Geffen School of Medicine, UCLA, USA \\ ${ }^{\mathrm{d}}$ Division of Digestive Diseases, UCLA, USA \\ ${ }^{\mathrm{e}}$ Nutrition Innovation Centre for Food and Health, N. Ireland, UK \\ ${ }^{\mathrm{f}}$ Department of Food and Drugs, University of Parma, Italy
}

Received 14 May 2021

Accepted 15 September 2021

Pre-press 1 October 2021

Published 2 November 2021

\begin{abstract}
The gut microbiota plays a significant role in health and development from birth and continues to affect several processes throughout life and into old age. During both infancy and old age, the trajectory of the gut microbiota changes with contrasting consequences at both stages for the host. The infant gut is unstable, and colonization is influenced by a variety of perinatal and postnatal factors. Many of these factors can contribute to an altered microbiota profile in infancy which can be associated with negative consequences later in life such as allergies, obesity, and neuropsychiatric disorders. The late-life gut microbiota is influenced by physiological changes within the host, illness, diet and lifestyle that impact its composition and functionality. Indeed, reduced microbial diversity, loss of beneficial microorganisms and increased pathobionts are key signatures of the elderly microbiome. Such changes have been associated with degenerative diseases including inflammaging, Alzheimer's disease, Parkinson's disease, and increased risk of infection with Clostridioides difficile. Here, we examine early- and late-life factors that contribute to contrasting gut microbiota disturbances and the consequences associated with these disruptions. Finally, we provide compelling evidence of nutritional and probiotic/prebiotic interventions that may help alleviate the effects of gut microbiota changes into old age.
\end{abstract}

Keywords: Gut microbiota, early life, late life, gut-brain axis, diseases, prebiotics, probiotics

\section{Introduction}

With an estimated $10^{13}$ microorganisms, the human gut is recognized as one of the most densely populated ecosystems on the planet. It is home to microorganisms from all domains of life including

\footnotetext{
${ }^{*}$ Corresponding author: Catherine Stanton, Teagasc Food Research Centre, Fermoy, Co. Cork, Ireland. Tel.: +3532542606; E-mail: Catherine.Stanton@teagasc.ie.
}

bacteria, archaea, and eukarya along with prokaryotic and eukaryotic viruses. The microbiota refers to the 'living' component - bacteria, archaea, protists and fungi, while the microbiota and its combined nucleic acids, including eukaryotic and prokaryotic viruses, microbial metabolites and microbial structural elements are referred to as the gut microbiome [1]. It bestows a myriad of health benefits on its host [2]. Most information to date relates to its bacterial component, indeed, the gut microbiota contains 
100 trillion bacteria. The functions provided by these microorganisms include production of nutrients and bioactive metabolites that are essential for host health such as vitamins and short chain fatty acids (SCFAs). It is responsible for programming host immunity and plays an important role in maintaining intestinal barrier integrity. Through colonization resistance, it protects the host from pathogen colonization and infection. It regulates energy homeostasis and communicates with the central nervous system. Its dysfunction has been associated with many diseases including inflammatory diseases [3], cardiovascular disease [4], gastrointestinal diseases [5], neurological diseases [6], and metabolic syndrome and obesity [7]. However, not all studies report the same observations which could be a consequence of laboratory techniques used, geographical location/dietary patterns etc. of the cohort under investigation, and evidence for causality remains to be elucidated.

Despite our understanding of the role the gut microbiome plays in host health, describing the healthy gut microbiome at any stage of life has proven extremely challenging for scientists. This is due to the vast inter-individual variation of the gut microbiota. Indeed, the gut microbiome could be described as a malleable, emergent system within the body influenced by many factors including host genetics [8], diet [9], stress and emotions [10], illness [11], antibiotics [12, 13], hormonal changes [14], to name but a few. Its establishment at birth is also influenced by a number of factors from birth mode to gestational age and type of feeding. Yet, correct microbial establishment in early life has been demonstrated to be central to the immunological, cognitive and metabolic development of the child, whereby altered seeding of this ecosystem during the first days of life can have longterm health consequences, such as predisposition to many disease states later in life.

The established healthy gut microbiota throughout adulthood is marked by a gut microbial diversity and richness that is significantly reduced in several disease states. Furthermore, certain bacterial members, beyond the noted probiotic members bifidobacteria and lactobacilli, are now linked with beneficial effects on the host including members of Ruminococcaceae, Lachnospiraceae, Christenellaceae, and Eubacteriaceae [15], which can be reduced in illness and certain conditions.

However, such signatures of a healthy gut microbiome have been shown to wane in later life - with loss of beneficial gut members, increased pathogens, and reduced microbial diversity representing common features of the elderly microbiota. Indeed, altered microbiota composition as a result of health perturbations at an advanced age induces a shift in the bacterial-host relationship from a symbiotic to a non-desirable/pathogenic one. Whether the extent of these changes in old age is linked to the establishment of the infant gut microbiota is as yet unknown as this science is still too young [16]. However, understanding the trajectory of the gut microbiome in infancy and old age, the two extremes of life, is vital to ensuring the optimal health of the host throughout its life cycle, given that physiological and external factors at both stages render significant consequences for the gut microbiome and subsequently host health.

With this in mind, this review aims to summarize recent findings on the factors that influence microbial development in early- and late-life, and disease states that may arise as a cause of perturbations to this delicate ecosystem. The review highlights the centrality of the gut microbiota in human health at the most vulnerable stages and discusses nutritional and probiotic/prebiotic interventions which may alleviate the consequences of gut microbiome dysbiosis in later life.

\section{The microbiota in early life}

\subsection{The development of the infant gut microbiota}

One of the most critical developmental events in early life is the bacterial colonization of the infant gut. The direct microbiota-host interactions of this biological 'superorganism' serve to seed immunological, cognitive and physiological development where this delicate ecosystem is perturbed, disease often ensues [17]. According to the long accepted sterile womb paradigm, the human fetus develops in a sterile environment and microbial colonization of the gastrointestinal (GI) tract occurs by both vertical and horizontal transmission during and after birth [18]. Recent studies have begun to contest this belief however, with findings (often controversial) reporting the presence of bacterial communities in the placenta, amniotic fluid and meconium [19], suggesting this colonization process in fact begins in utero [20].

Whilst it has been reported to have six times less OTUs (operational taxonomic units) than adults, the early infant gut microbiota is a highly dynamic entity which develops rapidly over the first two years of life 


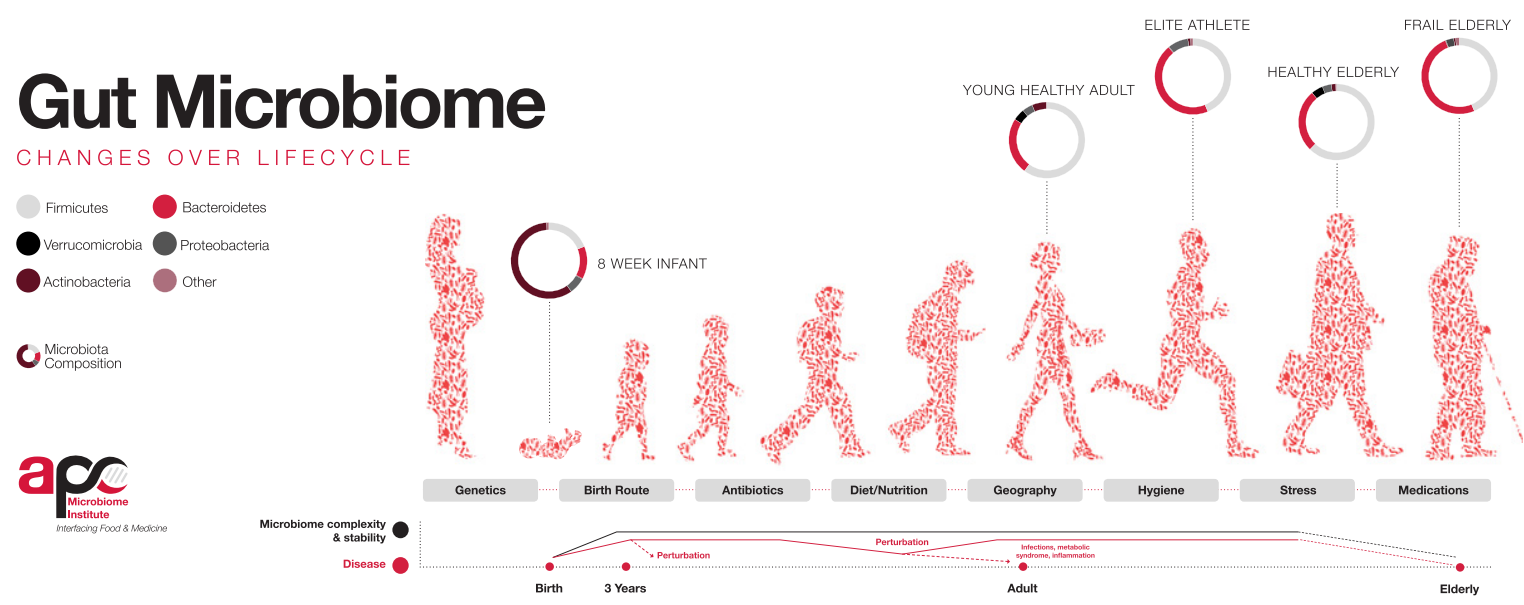

Fig. 1. Factors influencing the colonisation of the gut microbiota throughout life. Bacterial diversity increases from infancy until it matures at $\sim 3$ years of age and resembles an adult-life composition. Following adulthood, diversity again begins to decline with age. Source: APC Microbiome Ireland, 2018.

[21, 22]. Following normal vaginally delivered birth, the infant GI tract is swiftly colonized by an arsenal of bacteria, which is influenced by factors such as mode of delivery, gestational age, antibiotic exposure, diet, close family members and exposure to animals (Fig. 1). The aerobic environment of the infant gut following birth influences the initial colonizers which are facultative anaerobes such Proteobacteria (Enterobacteria) and Firmicutes (Streptococcus, Staphylococcus). These microbes produce a reduced, oxygen-deficient environment favourable for later colonization by Actinobacteria (Bifidobacterium), Clostridium, Lactobacillus, Ruminococcus, Bacteroidetes (Bacteroides) and Escherichia [23-25]. At $\sim 1$ month after birth, the diversity of the infant gut is increased and dominated by Actinobacteria (Bifidobacterium), Bacteroidetes (Bacteroides) and Gammaproteobacteria (Enterobacteria) which are required for the metabolism of specific carbohydrates found in breastmilk [22]. Following the introduction of solid foods at $\sim 6$ months, the infant gut shifts again with relative abundances of Bifidobacterium and Clostridiales decreasing, and Firmicutes levels increasing [26]. At the end of the first year of life, microbiota profiles display inter-individual variation but begin to converge towards that found in an adultlike GI tract [27].

Alpha-diversity ( $\alpha$-diversity) and beta-diversity ( $\beta$-diversity) are measurements allowing for a higherlevel description of the microbial communities in a sample. They measure microbial diversity or evenness, and variation, respectively between different environments, to display a broad change in microbial communities, rather than abundance or specific taxa. The $\alpha$-diversity of the gut microbiota increases and $\beta$ diversity decreases as the infant ages, and microbial profiles become more complex and more dissimilar between individuals [28], until the infant gut microbiota stabilizes and reaches an adult-like composition and diversity at about two to five years of age $[29,30]$. The exact time point of maturation remains unclear however, and findings are not universal. Studies have reported the gut incapable of reaching compositional and functional maturity before the age of four [31], the age of five [32], and even before pre-adolescence, with 7-12 year olds being found to possess significantly lower levels of Bacteroides spp. and more complex composition compared to adults, suggesting ongoing microbial development [30]. On the contrary, a 2019 study reported a cohort of 281 school-aged children between six and nine years old to have an adult-like alpha diversity and a similar functional repertoire to that of adults [33], whilst a 2020 study reported four-year olds to have an adult-like gut microbiota, with significantly increased levels of adult gut-dominating phyla Bacteroidetes and Firmicutes and decreased infant-gut phyla Actinobacteria and Proteobacteria [34].

\subsection{Factors that influence the early gut microbiota}

\subsubsection{Gestational age at birth}

Gestational age is a major determinant in the establishment of the neonatal gut microbiota $[34,35]$ 
and may continue to influence this process up until four years of age, with the alpha diversity of fullterm infants being substantially higher than that of pre-term infants [36]. Disruption to critical developmental stages of the final trimester of pregnancy due to premature birth result in infants possessing an immature GI tract with delayed bacterial colonization, aberrant intestinal barrier function, and poor nutrient-absorbing capabilities [37]. Aberrant gut physiology predisposes pre-term infants to illnesses such as systemic inflammation, sepsis and necrotizing enterocolitis (NEC) due to a 'leaky gut' and increased translocation of microorganisms into the bloodstream [38].

NEC is a life-threatening GI emergency, and one of the leading causes of premature infant death, with an incidence rate of between $2-13 \%$ and a mortality rate of up to $45 \%[39,40]$. Whilst antibiotics are commonly used to treat NEC, recent studies have shown promise with probiotics containing both Lactobacillus and Bifidobacterium being reported to reduce the incidence of the disease in pre-term infants by up to $50 \%$ [41]. Such results have meant that many neonatologists now consider it almost "unethical not to treat" premature babies with probiotics following birth.

The pre-term infant gut microbiota remains largely understudied; however, it is postulated that it is uncharacteristic relative to the full-term counterpart, being largely unbalanced and lacking in microbial diversity $[42,43]$. This may be due to the frequent delivery of premature infants by caesarean-section (CS) and an almost universal exposure to the microbiologically restrained environment of the neonatal intensive care unit and exposure to antibiotics in the first days of life [44]. Intestinal microbial colonization of preterm neonates has been reported to occur in a four-phased pattern, in the first 50 weeks post-birth as indicated by the dominance of Staphylococcus, Enterococcus, Enterobacteriaceae and Bifidobacterium [45]. The pre-term GI tract is reported to be primarily dominated by Proteobacteria and Firmicutes and members of the Enterobacteriaceae family [46, 47]. High levels of inter-individual variation have been reported between microbiota profiles of these infants; however, abundances of the beneficial commensals Bifidobacterium, Bacteroides and Lactobacillus are consistently reduced compared to full-term infants [22, 36, 46]. Furthermore, the abundances of potentially pathogenic bacterial groups such as Enterococcus, Klebsiella, Staphylococcus, Streptococcus and Clostridium spp. are increased in the pre-term infant gut [47,48], although, breastfeeding has been shown to be capable of restoring the gut-microbiota to that of a full-term infant, by significantly increasing levels of Bifidobacteriaceae and reducing Staphylococcaceae and Clostridiaceae $[44,49]$.

\subsubsection{Birth mode}

Another pivotal factor in shaping the infant gut microbiota is birth mode. Vaginally-delivered (VD) infants are exposed to the vaginal microbiota of the mother, and consequently, these infants initially harbour microbial communities that resemble the maternal vaginal microbiota such as Escherichia, Bifidobacterium, Lactobacillus, Bacteroides, Shigella and Prevotella [50-52]. VD infants are widely reported to display higher taxonomical diversity than that of infants born by CS [52, 53], and CS delivery has been associated with the development of non-communicable diseases such as asthma [54], eczema [55], allergies [56], adiposity [57] and diabetes [58] later in life.

Infants born by CS do not come into direct contact with the maternal birth canal and as a result acquire microbial communities from alternative sites such as the maternal skin microbiota and the hospital environment [29]. As a result, CS-born infants harbour gut bacteria such as Enterococcus, Staphylococcus, Streptococcus, Propionibacterium and Klebsiella spp. [51, 52, 59], and lower abundances of Actinobacteria (Bifidobacterium) and Bacteroidetes (Bacteroides) than VD-born infants [53]. CS infants have been associated with higher levels of opportunistic pathogens such as Clostridioides difficile and Lactobacillus genera, which coincide with lower luminal SCFA levels and higher $\mathrm{pH}$ due to decreased abundances of Actinobacteria and Bacteroidetes [60]. Alternatively, microbial populations of the VD infant GI tract such as Bacteroides fragilis and Bifidobacterium spp. produce SCFAs which maintain a lower intestinal $\mathrm{pH}$ that inhibits the growth of pathogens such as Clostridium perfringens $[60,61]$. CS-born infants have a delayed bacterial colonization and lower microbial diversity; however they eventually 'catch up' [61], and birth mode-related compositional differences have been shown to largely diminish in the first two years of life [62]. More recently, we have shown that $\mathrm{C}$-section in mouse models results in enduring effects on physiology and behaviour. [63]. Whether such effects also occur in humans requires further investigation. 


\subsubsection{Antibiotic intervention}

Premature birth and CS delivery are often confounded with antibiotic administration for the treatment of infections [64]. Early life antibiotic interventions have been shown to influence the gut microbiota, delaying microbial maturation for between six to 12 months after birth and causing significant alterations in the bacterial taxa over the first two years of life [62]. Additionally, antibiotic treatments have been linked to adverse health outcomes in later life such as adiposity [65] and the development of allergies and asthma [66]. Decreased microbial diversity has been associated with antibiotic treatment [67], and infants receiving antibiotics host lower abundances of Bifidobacterium, Bacteroides and Lactobacillus and increased levels of Proteobacteria and Firmicutes such as Clostridium and Staphylococcus $[68,69]$. Intrapartum antibiotic prophylaxis (IAP) is a common antibiotic treatment to which neonates are exposed and is administered to group B Streptococcus positive mothers, to reduce the risk of early onset neonatal sepsis [70]. IAP treatment in the mother has been reported to subsequently affect the infant developing gut microbiota, by causing a diminution in the relative abundances of Bifidobacterium spp. and Bacteroidetes and increased Proteobacteria and Enterobacteriaceae family members [71, 72]. Reduced phylogenetic diversity and richness associated with antibiotic exposure have been reported to be dependent on the duration of treatment [64], however influences of antibiotics on the developing infant gut microbiota have been shown to occur irrespective of infant health [73]. Furthermore, the increased relative abundances of Proteobacteria namely Enterobacteriaceae by early exposure to antibiotics promote a pro-inflammatory state, inducing a microbial imbalance in the developing gut [74], which requires prolonged recovery time compared with that of antibiotic-treated adults [75].

In addition to alteration of the infant developing intestinal microbiota, antibiotics also pose the threat of enriching the reservoir of antibiotic resistance genes (ARG, also termed 'the resistome') which is easily influenced in early life [76]. Multidrug-resistant members of the genera Escherichia, Klebsiella and Enterobacter which are common amongst nosocomial infections, have been reported to dominate the pre-term gut microbiota [77]. Further, infants exposed to IAP antibiotics have been reported to have significantly increased abundances of ARG [78], with one study reporting that out of 241 AGR genes identified, $29 \%$ and $25 \%$ were encoded by
Escherichia and Staphylococcus, respectively [79]. Studies of antibiotics on the developing infant gut microbiota and resistome warrant further investigation.

\subsubsection{Infant diet}

Milk is the first food to which the infant is exposed postpartum and it is widely understood to directly influence establishment of the gut microbiota $[80,81]$ and may continue to do so throughout early life [25]. Interestingly, mode of feeding in early life and gut microbiota composition at six to nine years have been significantly, positively correlated [33]. Breastmilk contains $>700$ bacterial species at a concentration of $\sim 1000$ colony forming units $(\mathrm{CFU}) / \mathrm{ml}$, therefore breast-fed infants are estimated to ingest $\sim 800,000$ bacteria a day [82].

Often regarded as the 'gold standard' for infant nutrition, breast-milk has been widely reported to provide the infant with both short- and long-term health benefits such as reduced susceptibility to morbidity, childhood obesity, GI disease and allergies [83, 84]. Breastmilk aids in "jump-starting" early life by providing the new-born infant with a plethora of bioactive molecules such as human milk oligosaccharides (HMO), IgA and essential fatty acids which, in addition to optimally shaping the infant gut microbiota, influence cognitive development and maturation of the immune system [85-87]. The maternal milk microbiota is primarily composed of Staphylococcus and Streptococcus, followed by Bifidobacterium and Lactobacillus, Enterococcus, and members of the Enterobacteriaceae family [88-90], which coincides with these being amongst the earliest colonizers of the infant gut microbiota [91]. The transfer of microbes from mammary gland to infant gut has been suggested to occur via vertical transmission [75, 92], and infants who are breast-fed during their first month of life have been observed to share $28 \%$ of their fecal microbiota with their maternal milk microbes [81]. Infant formula is often used in lieu of breastmilk in instances where breastfeeding is not possible due to an unavailability of milk or maternal reasons. Whilst it is a sufficient source of nourishment for the newborn, infant formula is nutritionally inferior, lacking the diversity of components of breastmilk, such as HMOs which serve to promote the colonization of probiotic Bifidobacterium and Bacteroides commensals [93]. Many studies exist that report differences in the gut microbiota of breast-fed and formula-fed infants, with those who are formulafed possessing a more complex microbiota with 
higher relative amounts of facultative anaerobes such as Proteobacteria and Firmicutes [69, 94]. Contrastingly, breast-fed infants possess a less stable, simpler microbiota, with significantly higher abundances of Bifidobacterium and Bacteroides than formula-fed infants $[50,95,96]$. Breast-fed infants are reported to have lower Streptococcus, Viellonella, Clostridiodes and Enterococcus levels [97], whilst formula-fed infants have been shown to possess higher abundance of $C$. difficile [91]. Previous findings suggest that around two years of age, the observed differences between breastfed and formula-fed infants diminish, and the bacterial communities more or less coincide to resemble an adult-like microbiota [95].

\subsubsection{Prenatal stress}

There is increasing recognition of prenatal stress as a disruptive factor in the development of the infant gut microbiota [98]. Prenatal exposure to stress has been linked to health issues such as pre-term birth [99], lower birth weight [100], as well as obesity and metabolic dysfunctions later in life [101]. Additionally, infants pre-exposed to stress in utero have been linked to increased antibiotic treatments in childhood [102] and higher GI disturbances such as diarrhoea and gastroenteritis during the first three months of life [103]. Prenatally stressed infants have been reported to host microbial communities that are characteristic of increased inflammatory levels including higher abundances of pathogenic Proteobacteria (Escherichia, Enterobacter and Serratia related) and also lower abundances of lactic acid bacteria (Lactobacillus, Lactococcus), bifidobacteria and Akkermansia [103, 104]. Interestingly, a recent study reported increased maternal hair cortisol concentrations to be negatively associated with Actinobacteria, Proteobacteria and Firmicutes levels, although findings were not significant [104].

Infants exposed to prenatal stress have also been shown to have increased levels of Firmicutes (Weissella) and Enterobacteriaceae (unclassified genera) in the meconium [105], the latter of which has been found to be characteristic of depression in later life [106]. Animal studies have also found similar results, whereby prenatally stressed monkey infants were seen to have an altered microbiota composition compared to control infants, with significantly lower levels of lactobacilli and bifidobacteria [107]. Further, consequent to these shifts in gut microbial communities as observed in prenatally stressed infants is an aberrant gut physiology, with increased permeability and reduced gut barrier integrity, leading to the predisposition of various GI and immune diseases later in life [108].

Based on a series of preclinical studies, the gut microbiota has also been postulated to be a paramount contributor to the neurodevelopment of the infant via the gut-brain axis [109]. Prenatal stress in mice has been shown to alter the gut and vaginal microbiota of the mother and consequent transmission of these dysbiotic microbiota to the infant has been implicated in increased risk of neurodevelopmental disorders through a disruption in their own microbiota development (discussed further below) [110, 111]. Maternal prenatal stress and subsequent disruption of the offspring developing gut has also been speculated to delay the development of the hypothalamus-pituitary-adrenal axis (HPA), a series of mechanisms which have been implicated in aberrant behavioural and emotional development of the child [112].

\subsection{Diseases associated with the gut microbiota in early life}

\subsubsection{Allergies}

In recent years, the incidence of IgE-mediated atopic diseases such as asthma, atopic dermatitis (eczema) and food allergies has risen sharply [113]. Reduced bacterial diversity in the first year of life is associated with increased risk of allergies in first six years of life [114], and increased bacterial richness at three months may provide the infant with up to $55 \%$ reduced risk of developing a food allergy in the first year of life [115]. In general, children with food allergies have been reported to have an increased Firmicutes/Bacteroidetes ratio, with increased levels of genera such as Bifidobacterium, Clostridium, Enterococcus, Lactobacillus and Akkermansia and under-representations of Streptococcus and Bacteroides [116]; however, exact microbiota profiles depend on the type of food allergy (e.g. wheat, peanut soy, etc.) [117].

Gut microbial communities of children with eczema have been characterised by a lower alpha diversity and lower relative abundance of Actinobacteria, whilst Bacteroidetes were highly enriched, compared to healthy controls [118]. Probiotics have shown promise in this area, with Lactobacillus fermentum and Lactobacillus salivarius both capable of significantly reducing the severity of eczema in children [119]. Additionally, Lactobacillus plantarum was found to improve eczema severity, by lowering IL- 
4, IL-17 and IFN- $\gamma$ levels [120]. CS delivery and subsequent colonization of $C$. difficile in the infant gut has been linked to development of asthma in six to seven year olds, whilst vaginally-born children were only pre-disposed if a parent suffered with an atopic disease [121]. A putative therapeutic role for probiotics in the treatment of asthma has been suggested [122].

\subsubsection{Obesity}

In parallel with the increased consumption of the 'Western diet' rich in processed foods, is an increasing prevalence of the worldwide "globesity" epidemic. According to the World Health Organisation, approximately 38 million children under the age of five were reported to be overweight in 2019, representing a three-fold increase since the 1970s [123]. Obesity and adiposity can have major health implications such as diabetes and cardiovascular disease [113]. Whilst often due to an increased energy intake and reduced energy output, studies over recent years have begun to uncover a role of the gut microbiota in the process [124], with mounting evidence suggesting the establishment of the gut microbiota in early life plays a pivotal role in adiposity and the development of obesity in childhood [125].

Obesity has been widely associated with alterations in the gut microbiota in adults, albeit findings are inconsistent. Some studies report an increased Firmicutes/Bacteroidetes ratio, as a result of obesity [126-128], and other studies report the converse, or, no relationship $[129,130]$. Consequently, relative changes in these phyla cannot be currently classified as a biomarker for obesity. Whilst findings of microbiota alterations in children due to obestiy are limited, it has been suggested that relative abundances of Escherichia coli and Staphylococcus are increased, whilst Bifidobacterium counts are reduced [131, 132]. Additionally, levels of Dorea have been reported to be increased, whilst the genera Ruminococcus, Akkermansia and Parabacteroidetes were found to be decreased in obese children compared to non-obese children [133]. Predisposition to adiposity may occur in utero, with infants' fecal microbiota profiles being reported to be related to maternal BMI, weight and weight gain during pregnancy [134]. Infants of overweight mothers have been shown to have an altered gut microbiota, with higher levels of Bacteroides, Enterococcus and Staphylococcus over the first six months of life [135, 136]. Moreover, feeding has also been reported to influence the prevalence of obesity in childhood, with infants who are breastfed being less likely to develop obesity than their formula-fed counterparts [137]. This may be in part, explained by lower abundance of Bifidobacterium observed in formulafed infants versus breastfed infants which has been linked to increased adiposity at 18 months [138]. CS delivery has also been associated with a higher prevalence of adiposity during childhood, which may extend into adulthood [139]. Antibiotic exposure in infancy has been associated with adiposity and obesity later in childhood, which may occur through a disrupted microbial colonization [140, 141], however, it has been purported that the GI microbiota become less susceptible to alterations by antibiotics as it matures [142]. Interestingly, antibiotics and adiposity have been reported to have stronger links in boys which may be due to sex-specific GI responses such as antibiotic drug metabolism or host-microbe interactions [143, 144]. Moreover, only high levels of antibiotic treatments ( $\geq 4$ courses) were linked to a higher body mass index trajectory in childhood in Irish children between the ages of two and five years [142].

\subsubsection{Neuropsychiatric disorders}

The gut-brain axis is a bi-directional communication network involving several aspects of the nervous system and the gut microbiota [145]. The GI tract is capable of influencing the brain in terms of mood states, which in turn can have consequent effects in GI motility, secretion and immune function [146]. Evidence suggests a co-maturation between the two in infancy [147]. Behavioural and cognitive processes may affect brain-gut axis function and have been implicated in functional disorders such as irritable bowel syndrome and increased intestinal permeability [108]. Conversely, dysbiosis of the gut has been associated with CNS disorders such as autism, anxiety and depression [148]. The HPA axis is one arm of the human stress response system, activation of which involves stimulation of the hypothalamus and a downstream systemic release of cortisol [146]. The other arm is the sympathetic nervous system (SNS), which is able to alter gut function, including gut permeability ([149], reviewed in [150]). Increased translocation of bacteria across the intestinal lumen as seen in prenatally stressed mice results in the upregulation of inflammatory markers and proinflammatory cytokines which are potent activators of the HPA axis [151]. Disruptions to the HPA axis caused by variations in gut microbiota have been shown to exacerbate anxiolytic behaviours in mice [152]. In addition, exaggerated responses of the SNS have also 
been demonstrated in chronic anxiety and implicated in the aetiology of cardiovascular disease [153].

As aforementioned, intestinal microbial communities are known to be central to the maturation of an infant's GI tract and immunity, with this extending to aspects of cognitive development. Mounting evidence suggests that microbial colonization of the GI tract in early life contributes to the parallel sequential maturation of the brain up to three years of age [147], and the gut microbiome composition of infants has been implicated in childhood temperament, with greater sociability being associated with a higher gut phylogenetic diversity [154]. Moreover, a 2018 study reported high GI alpha-diversity to be negatively associated with cognitive performance and reported the gut microbiota composition and diversity at one year of age to be predictive of cognitive performance at two years of age [155]. The same study also found infants with higher abundances of Bacteroides and lower levels of Faecalibacterium to have better cognitive function.

More recently, research has begun to unveil the role of the gut microbiota in neuropsychological disorders, further highlighting the possible pathophysiological role of this biological 'supersystem' in human health and disease. Increased abundances of Bacteroidetes (Bacteroides uniformis, Bacteroides ovatus) and Sutterella stercoricanis have been reported in children with attention deficit disorder [156]. Alterations in the gut microbiota have also been implicated in schizophrenia [157], with a recent study reporting the schizophrenia gut to be specifically enriched in Streptococcus vestibularis [158]. Gut dysbiosis has also been implicated in autism spectrum disorder, with severely autistic children harbouring higher levels of Bacteroidetes, Clostridium, Lactobacillus spp. and Desulfovibrio spp. and lower levels of Firmicutes and Bifidobacterium in comparison to control, non-autistic subjects [159-161].

Animal studies have also highlighted the importance of gut-brain interactions in early life development, and germ-free (GF) mice have been shown to have aberrant anxiety responses [162]. Remarkably, when adult GF mice are inoculated with specificpathogen-free mice microbiota in adulthood, altered anxiolytic phenotypes are seen to persist, suggesting that a critical window exists for the development of stress systems in early life [163]. Studies reporting the gut-brain axis in the context of neuropsychiatric disorders in childhood are limited and underlying mechanisms of the development of these disorders have yet to be elucidated. It is worth noting however, that the 'medical accessibility' of the human gut microbiota in comparison to the human genome may represent a promising therapeutic strategy for the treatment and prevention of neuropsychiatric disorders in the future [113].

\section{The microbiota in later life}

\subsection{The gut microbiota in old age}

While the healthy adult gut microbiota is relatively stable over long periods [164], ageing ( $>65$ years generally) has a significant impact on its composition and functionality [165]. Key signatures of the elderly gut microbiota include increased abundance of opportunistic pathogens, a decrease in microbiota diversity, reduction in SCFA-producing species, and an increase in facultative anaerobes [166-168]. A change in the ratio of Firmicutes to Bacteroidetes has been observed in older individuals consuming a Western-type diet, which decreased from 10.9 in adults (25-45 years) to 0.6 in the elderly cohort (70-90 years), resembling the ratio of 0.4 in infants (three weeks to 10 months old) [169]. Inter-individual variation is also extensive in the elderly group and much greater than that observed in healthy adults, with Firmicutes proportions in an elderly Irish cohort ranging from $7 \%$ to $94 \%$, and the dominant phylum, Bacteroidetes, ranging from $3 \%$ to $92 \%$ [170]. Other observed trends include decreases in Bifidobacterium, Faecalibacterium groups, and Blautia coccoides (Clostridium XIVa group) [171-175]. Country-specific trends have also been observed and are discussed in detail by Salazar et al. [165]. As an example, the Bacteroides-Prevotella group has been found to be over-represented in Irish [170], Japanese [173], German, Swedish [176], Austrian [177] and Finnish [178] elderly cohorts but under-represented in English [179], Italian [176] and Spanish [167] cohorts. However, as Salazar et al. state, it is unclear if such differences are related to different geographical populations or the consequences of methodological differences [165].

\subsection{Factors that influence the elderly gut microbiota}

Both physiological and lifestyle changes that ultimately influence diet and nutrition undoubtedly contribute to the changes in the ageing gut microbiota. In terms of physiological alterations, these can 
include changes in appetite, mood, medications, changes in salivary function and dentition, which can lead to imbalanced nutrition due to poor dietary choices, and changes in gastrointestinal motility that can cause a reduction in digestion and absorption of nutrients [180]. Medication and drugs are more frequently prescribed for the elderly and these too may impact the gut microbiota. For example, it has been reported that polypharmacy in older hospitalized patients significantly associated with gut microbiota dysbiosis (reduced species richness and significant variations in the relative abundances of a large number of taxa), while, in contrast, such dysbiosis was not found in active healthy older people without polypharmacy [181]. In old age, the normal functioning of the immune system also wanes, which can contribute to increased infection with gut pathogens [173]. The elderly GI tract is also marked by increased immune activation and a thinning of the intestinal lining [182]. In terms of lifestyle, changes in living conditions have been shown to significantly influence the elderly gut microbiota as a consequence of dietary changes [172]. Indeed, distinct gut microbiota profiles were observed across elderly individuals either living in the community, attending day-hospital, in rehabilitation or long-stay residential care [172], and these profiles overlapped with the diets associated with these locations (low fat/high fibre, moderate fat/high fibre, moderate fat/low fibre, high fat/low fibre, respectively). The low-fat/high fibre diet of community dwellers correlated with a gut microbiota that resembled that of healthy young adults. In contrast, the high fat/low fibre diet of long-stay care residents correlated with a gut microbiota that was less diverse than that of healthy community dwellers. Loss of community-associated microbiota in long-stay care residents such as Prevotella and Ruminococcus associated with frailty. In another study, the important butyrate producer, Faecalibacterium prausnitzii was less abundant in frailer individuals while the pathogens Eggerthella lenta and Eubacterium dolichum were more abundant with frailty [183]. Likewise, residents of an elderly nursing home in America consuming a typical low-fibre-nursing-home diet had lower levels of butyrate producers and greater abundances of dysbiotic species [184]. A more recent study by the same group revealed that the dysbiotic gut microbiota of elderly nursing home residents - characterised by pro-inflammatory bacteria and reduced anti-inflammatory microbes - associated with $C$. difficile colonization [185].

\subsection{Degenerative conditions and diseases associated with the elderly gut microbiota}

\subsubsection{Clostridioides difficile infection}

The most common bacterial infection of the elderly, particularly those that are institutionalised, is $C$. difficile, causing mild to fatal diarrhoea. Mortality risk from $C$. difficile infection (CDI) increases with age [186]. Carriage rate of the pathogen has been shown to increase to $21 \%$ in institutionalised elderly individuals compared with a carriage rate of $1.6 \%$ in community-living elderly individuals [187]. Gut microbiota disruption as a consequence of antibiotic treatment is a leading factor in CDI. The resulting decrease in microbiota diversity and the elimination of health-associated taxa enable $C$. difficile to become established in the gut [188]. Yet, as previously mentioned, the dysbiotic microbiota of elderly nursing home residents also allows $C$. difficile to flourish [185]. CDI in hospitalised elderly individuals was also associated with under-representation of gut microbes with potential protective properties including Bacteroides, Alistipes, Lachnospira, and Barnesiella, and overrepresentation of opportunistic pathogens including Klebsiella, Escherichia/Shigella, Sutterella, Enterococcus, Citrobacter, Veillonella, Proteus, Helicobacter, Morganella, Hafnia, Corynebacterium and Staphylococcus [189].

\subsubsection{Inflammaging}

Inflammaging is described as the "long-term result of the chronic physiological stimulation of the innate immune system, which can become damaging during ageing ..." [190]. It is a risk factor for numerous diseases including cardiovascular disease, diabetes mellitus, chronic kidney disease, cancer, dementia, sarcopenia, and depression [191]. Given the impact of the gut microbiota on local and systemic immune responses [192], it is unsurprising that the gut microbiota plays a central role in inflammaging. Indeed, the gut microbiota changes that occur with ageing promote a pro-inflammatory environment. Evidence of the inflammaging potential of the elderly gut microbiota became apparent when transfer of an aged microbiota to young GF mice resulted in inflammaging in the young mice [193]. Low levels of Akkermansia and increased levels of TM7 and Proteobacteria were associated with the inflammaging effect of the aged microbiota following transfer. It is interesting to note that centenarians and semisu- 
percentenarians have been shown to have increased levels of health-associated bacteria such as Akkermansia, which could be a signature of longevity.

Furthermore, SCFA production in the elderly gut has been shown to decrease with age. This could be due to a drop in the metabolic activity of certain microbiota as observed in elderly individuals $>80$ years of age [192] or the result of a reduction in SCFA-producing bacteria due to a low-fibre diet [170]. Thus, unsurprisingly, aging has been associated with a progressive and statistically significant reduction in fecal SCFAs [194]. Yet, SCFAs play an essential role in immune homeostasis. For example, in mice, microbiota-derived SCFAs have been shown to promote Th1 cell IL-10 production via Gprotein coupled receptor 43 (GPR43), which results in intestinal homeostasis [195]. The SCFA butyrate has been shown to down-regulate the expression of genes involved in inflammatory pathways in noninflamed intestinal tissue [196]. The results suggest that the low levels of SCFA-producing bacteria in the elderly gut, and consequently reduced SCFAs, contribute to inflammaging.

Data from a non-human primate model suggest that aging increases colonic permeability as a result of remodeling of intestinal tight junction proteins [197]. Moreover, gut microbiota lipopolysaccharide (LPS) was reported to accelerate inflammaging in mice [198], suggesting that the gut microbiota can contribute to inflammaging via translocation of LPS across the poor intestinal barrier in the aged population.

\subsubsection{Alzheimer's disease}

The gut-brain axis refers to the network of connections between the gut microbiota and the brain $[199,200]$. As a consequence, the gut microbiota influences the central nervous system (CNS) through a variety of mechanisms. The gut microbiota can produce neurotransmitters such as gamma aminobutyric acid (GABA) [201]: Microbial metabolites such as SCFAs, indole, secondary bile acids, tyramine, p-aminobenzoate, and $\alpha$-tocopherol promote serotonin biosynthesis in colonic enterochromaffin cells [202]. In preclinical models, SCFAs have been shown to influence the CNS by regulating neuroplasticity [203, 204]. Numerous studies have correlated the gut microbiota with neurodegenerative diseases such as Alzheimer's disease and Parkinson's disease $[199,205]$. Alzheimer's disease is the most prevalent form of dementia affecting older people [206] and is characterized by plaques in several parts of the brain. These plaques are composed of $\beta$-amyloid $(\mathrm{A} \beta)$ fibrils and hyperphosphorylated tau proteins. Interestingly, $A \beta$ 's activities have been recently proposed to possess a protective/damaging duality. $A \beta$ has been nominated as an antimicrobial peptide, which elicts a protective role in innate immunity. Recent studies of infection in mouse and worm models of Alzheimer's disease revealed that $A \beta$ protects against microbial infection, via reduced microbial adhesion to host cells. Further, amyloid precursor protein (APP) - knockout (APP-KO) mice were found to display lower survival rates following bacterial infection [207]. It is also believed that gut microbial LPS and amyloids may contribute to the pathogenesis of Alzheimer's disease in older individuals by passing through the leaky gut barrier [206]. Indeed, bacteria produce a range of amyloids that have been implicated in the pathogenesis of Alzheimer's disease. It is also hypothesized that increased inflammation in the gut, and the dysbiosis that ensues promotes the production of antimicrobial calprotectin, which supports amyloid fibril formation in the gut and the brain [206]. The gut microbiota of cognitively impaired, amyloid-positive patients was found to harbor an increased abundance of proinflammatory bacteria (Escherichia/Shigella) and a reduction in anti-inflammatory bacteria [208]. Furthermore, in a mouse model of Alzheimer's disease, transfer of a healthy microbiota via fecal microbiota transfer reduced amyloid and tau pathology in the recipient animal suggesting that restoration of intestinal homeostasis may prove beneficial for Alzheimer's disease treatments [209].

\subsubsection{Parkinson's disease}

Parkinson's disease is a very common agerelated neurodegenerative disorder. It involves the accumulation and aggregation of alpha-synuclein ( $\alpha$-syn) within the CNS and other neural structures [210]. Gastrointestinal dysfunction is a feature of Parkinson's disease with patients reporting nausea, constipation, defecatory dysfunction, as well as irritable bowel syndrome [211, 212]. It has been proposed that inflammation stemming from gut microbiota changes may be a contributing factor to $\alpha$-syn misfolding [213, 214] and several studies have reported gut microbiota changes preceding or taking place during the disease [205, 215]. A 2015 study by Scheperhans et al. reported that the abundance of Prevotellaceae was reduced by $77.6 \%$ in Parkinson's disease patients compared with healthy controls. Furthermore, severity of postural instabil- 
ity and gait difficulty was positively associated with the relative abundance of Enterobacteriaceae [216]. Another study observed similar microbiota profiles in Parkinson's disease patients along with a reduction in Bacteriodetes, but the study also measured fecal SCFA levels and found that they were significantly reduced in the patients [217]. More recently, a 2020 study by Zhang et al. reported that eight inflammation-associated bacterial genera (Parabacteroides, Akkermansia, Coprococcus, Bilophila, Collinsella, Methanobrevibacter, Eggerthella, Adlercreutzia) may play a role in the progression of the disease [218]. Given that faecal microbiota transplantation in Parkinson's disease mice has been reported to exert neuroprotective effects [219], the gut microbiota may be a target in the treatment of the disease.

\subsection{Nutritional/probiotic interventions that modulate gut microbiota and health}

Dietary and therapeutic interventions with probiotics and prebiotics continue to generate promising results in terms of beneficially modulating the gut microbiota based on randomized, controlled trials in humans in many cases, resulting in improved clinical manifestations in the host. Fibre is essentially the food of the gut microbiota and is found in fruits, vegetables and cereals, thus increasing the servings of these consumed in the daily diet, increases fibre in the gut [220]. Growing attention is now being focused on enhancing fibre for modulating the microbiota-gut brain axis [221, 222]. Humans lack the necessary enzymes to degrade fibre but the gut microbiota encodes the enzymatic repertoire to breakdown fibre into fermentable monosaccharides [2], and the resulting end-products of microbial fermentation are SCFAs. Prebiotics are defined as "a substrate that is selectively utilised by host microorganisms conferring a health benefit" [223] and these can be added to the diet as supplements, while probiotics are defined as "live microorganisms which when administered in adequate amounts, confer a health benefit on the host" [224]. Probiotics can be taken as supplements or via probiotic-enriched foods, such as fermented milks and yoghurts [225].

Approximately, $30 \%$ of individuals over 50 years of age are said to fall short of several nutrients in their diet including fibre, B vitamins, folic acid, vitamin D and iron [226, 227]. Dietary fibre intake in the elderly should directly affect SCFA levels. This was confirmed in a study involving 32 institu- tionalised elderly subjects ranging in age from 76 to 95 years, which investigated the impact of different dietary fibres on fecal SCFA concentrations [228]. Indeed, potato intake was directly associated with SCFA concentrations, apple intake associated with propionate, cellulose associated with acetate and butyrate, and insoluble pectin partly associated with propionate. Therefore, ensuring the aging population consumes adequate fibre in the diet should go some way to preventing/delaying the potentially detrimental gut microbiota modifications observed in the elderly. However, changes in dentition etc. may preclude older individuals from consuming fibre-rich foods. In this case, prebiotics are a viable alternative.

Several studies have investigated the impact of prebiotic supplementation on the elderly gut microbiota as well as other parameters of host health, and the results have revealed the ability of prebiotics to increase beneficial gut bacteria, and improve immune parameters as well as certain clinical indices of old age [229]. For example, daily consumption of $5.5 \mathrm{~g}$ of the prebiotic galactooligosaccharides (GOS) by elderly volunteers for four weeks in a randomized, double-blind, placebo-controlled, crossover study significantly increased Bifidobacterium and Bacteroides and generated immune alterations [230]. Consumption of $4 \mathrm{~g}$ of GOS by men and women aged 50 years and older twice daily for three weeks in a randomized, cross-over study significantly increased fecal Bifidobacterium levels [231]. Continuous culture systems of fecal inocula from three volunteers representing different large bowel regions revealed increased butyrate levels in the vessel similar to the proximal colon. Daily consumption of the prebiotic fructooligosaccharides (FOS) also generated a bifidogenic effect with fecal bifidobacteria counts increased [232]. Following a randomized, double-blind, clinical trial to investigate the impact of prebiotic supplementation on frailty syndrome in the elderly, it has been reported that the prebiotic in question significantly improved exhaustion and handgrip strength following 13 weeks of daily consumption [233]. A more recent placebo-controlled, randomized, double-blind study reported that prebiotic supplementation in the elderly significantly reduced frailty levels, especially in individuals with higher frailty levels to begin with [234].

In the elderly, probiotic supplementation has been shown to increase beneficial bacteria in the gut and improve certain immunity parameters [229]. For example, daily consumption of Bifidobacterium lactis HN019 by elderly subjects (68 to 84 years 
of age) improved immunity [235]. Consumption of a probiotic mixture consisting of strains of Lactobacillus gasseri, Bifidobacterium longum, and Bifidobacterium bifidum by elderly volunteers in a randomized, double-blind, placebo-controlled crossover study, not only significantly increased IL-10 concentrations, but significantly increased beneficial bacteria including bifidobacteria, lactic acid bacteria and the butyrate producer $F$. prausnitzii [236]. Consumption of a probiotic-containing cheese in a randomized, controlled, cross-over clinical trial was associated with lower counts of $C$. difficile in the elderly volunteers [237]. However, a high dose of probiotics proved ineffective to prevent antibioticassociated diarrhoea in older people admitted to hospital in a multicentre, randomized, double-blind, placebo-controlled, parallel-arm trial [238]; despite this, a trend for reduced $C$. difficile diarrhoea was noted in the probiotic arm. A 2019 retrospective, case-control study by Nagamine et al. also reported that administration of a combination of probiotics has potential to reduce the risk of CDI in patients undergoing proximal femoral fracture surgery [239]. A probiotic-containing biscuit consumed daily for one month by elderly individuals in a randomized, double-blind, plaebo-controlled trial reverted age-related increases in a number of opportunistic pathogens including $C$. difficile [240].

Probiotics have also generated promising results in individuals suffering from cognitive decline. A double-blind, placebo-controlled clinical trial reported that $B$. breve A1 supplementation resulted in a significant improvement in cognitive function in older individuals with suspected mild cognitive impairment [241]. Synbiotics consist of probiotics and prebiotics which act synergistically on the host. Such a mixture was shown to improve constipation in individuals with Parkinson's disease in a randomized, double-blind, placebo-controlled trial [242]. Consumption of a multi-strain probiotic (Hexbio $\left.{ }^{\circledR}\right)$ by Parkinson's disease individuals in a randomized, controlled trial was shown to improve bowel opening frequency and whole gut transit time [243].

\section{Discussion}

The trajectories of the gut microbiota at infancy and old age, particularly in terms of $\alpha$-diversity, move in opposite directions. As the infant grows, the $\alpha$-diversity of the gut microbiota increases until it resembles that of an adult. In old age, $\alpha$-diversity is seen to decline. At a certain point, the ratios of Firmicutes to Bacteroidetes in infants and the elderly almost converge (0.4 and 0.6, respectively) [169]. But while the healthy infant gut microbiota goes on to acquire rich species diversity with an abundance of commensals and beneficial bacteria, the elderly gut microbiota is marked by reduced microbiota diversity, loss of beneficial members, and higher levels of pathogens/"undesirables". Many of these alterations have been linked with dietary changes in old age $[170,192]$, thus it has proven difficult to find associations between aging itself and specific microbiota changes [192]. But the impact of other factors that may inflict elderly individuals including loneliness and depression should also be investigated in terms of gut microbiota changes.

The acquisition of the healthy infant gut microbiota involves a delicate assembly of timely species where full-term, vaginally born, breast-fed infants are recognised as having the most favourable opportunities to acquire a microbiota that optimally benefits its host. This delicate assembly is thus compromised by several factors including gestational age at birth, birth mode, antibiotics, diet and prenatal stress. Indeed, preterm birth, CS delivery, antibiotic intervention, formula-feeding, and maternal stress during pregnancy, can each shape a microbiota that is less abundant in beneficial microbes, lacking in microbial diversity with an increased abundance of potentially pathogenic bacteria, alterations that resemble the ageing microbiota.

In the elderly, inevitable physiological changes associated with old age, lifestyle changes, illness and medication contribute to the altered microbiota composition and functionality. And in both age-groups, the aberrant microbiota alterations have been associated with diseases and conditions, even though the majority of these studies do not prove a causal effect. Indeed, association studies, while essential in cataloguing particular microbiota profiles and physiological signals, lack the specificity required to pin down the exact microbes responsible for these effects. But the reported associations are necessary to guide the way for causal studies in the highly complex biological system of a holobiont (host and microbiota together). In children, atopic diseases, neuropsychiatric disorders, and obesity have been linked with sub-optimal microbiota structures. The microbiota alterations in old age have been linked with degenerative conditions such as Alzheimer's and Parkinson's diseases and increased risk of infection with pathogens, especially $C$. difficile. 
In infants, time and dietary changes have seen the altered microbiota 'catch up' with its healthy counterpart although the full consequences of sub-optimal microbiota succession have yet to be delineated. In the elderly, dietary interventions, probiotics and prebiotics have generated promising results in terms of reversing age-related microbiota changes, which have manifested in improved clinical parameters such as reduced frailty and improved cognitive function, though it must be emphasized that evidence for causality is few and far between. As such, defining the links between association and causality in gut microbiota research at these delicate stages of life should enable scientists to develop strategic interventions that revert or prevent aberrant microbiota alterations, and thus provide a layer of protection against age-associated diseases.

\section{Acknowledgments/Funding}

This work was supported by Science Foundation Ireland [grant number SFI/12/RC/2273_P2] and VISTAMILK [grant number 16/RC/3835].

\section{Conflicts of interest}

The authors declare no conflict of interest.

\section{References}

[1] Berg, G., Mahnert, A. \& Moissl-Eichinger, C. Beneficial effects of plant-associated microbes on indoor microbiomes and human health? Front. Microbiol. 2014;5:15.

[2] Mills S, Stanton C, Lane JA, Smith GJ, Ross RP. Precision Nutrition and the Microbiome, Part I: Current State of the Science. Nutrients. 2019a;11(4):923.

[3] Clemente JC, Manasson J, Scher JU. The role of the gut microbiome in systemic inflammatory disease British Medical Journal. 2018;360:j5145.

[4] Peng J, Xiao X, Hu M, Zhang X. Interaction between gut microbiome and cardiovascular disease. Life Sciences. 2018;214:153-7.

[5] Gorkiewicz, G, Moschen, A. Gut microbiome: a new player in gastrointestinal disease. Virchows Arch - European Journal of Pathology. 2018;472:159-72.

[6] Tremlett H, Bauer KC, Appel-Cresswell S, Finlay BB, Waubant E. The gut microbiome in human neurological disease: A review. Annals of Neurology. 2017;81:369-82.

[7] Dabke K, Hendrick G, Devkota S. The gut microbiome and metabolic syndrome. Journal of Clinical Investigation. 2019;129(10):4050-7.
[8] Bonder MJ, Kurilshikov A, Tigchelaar EF, Mujagic Z, Imhann F, Vila AV, Deelen P, Vatanen T, Schirmer M, Smeekens SP, Zhernakova DV, Jankipersadsing SA, Jaeger M, Oosting M, Cenit MC, Masclee AA, Swertz MA, Li Y, Kumar V, Joosten L, Harmsen H, Weersma RK, Franke L, Hofker MH, Xavier RJ, Jonkers D, Netea MG, Wijmenga $\mathrm{C}, \mathrm{Fu}$ J, Zhernakova A. The effect of host genetics on the gut microbiome. Nat Genet. 2016;48(11):1407-12.

[9] David LA, et al. Turnbaugh, Diet rapidly and reproducibly alters the human gut microbiome. Nature. 2014;505: 559-63.

[10] Osadchiy V, Martin CR, Mayer EA. Gut Microbiome and Modulation of CNS Function. Comprehensive Physiology. p. $57-72$.

[11] McDonald D, Ackermann G, Khailova L, Baird C, Heyland D, Kozar R, Lemieux M, Derenski K, King J, Vis-Kampen $\mathrm{C}$, et al. Extreme dysbiosis of the microbiome in critical illness. mSphere. 2016;1:e00199-16.

[12] Iizumi T, Battaglia T, Ruiz V, Perez Perez G.I. Gut microbiome and antibiotics. Arch. Med. Res. 2017;48:727-34.

[13] Francino MP. Antibiotics and the human gut microbiome: Dysbioses and accumulation of resistances. Frontiers in Microbiology 2016;6:1543.

[14] Koren O, Goodrich JK, Cullender TC, Spor A, Laitinen K, Bäckhed HK, González A, Werner JJ, Angenent LT, Knight R, et al. Host Remodeling of the gut microbiome and metabolic changes during pregnancy. Cell. 2012;150: 470-80.

[15] Lordan C, Thapa D, Ross RP, Cotter PD. Potential for enriching next-generation health-promoting gut bacteria through prebiotics and other dietary components. Gut Microbes. 2020;11(1):1-20.

[16] Cryan JF, Boehme M, Dinan TG. Is the fountain of youth in the gut microbiome? J Physiol. 2019;597(9):2323-4.

[17] Kinross JM, Darzi AW, Nicholson JK. Gut microbiomehost interactions in health and disease. Genome Medicine. 2011;3(3):14.

[18] Moore RE, Townsend SD. Temporal development of the infant gut microbiome. Open Biology. 2019;9(9):190128.

[19] Perez-Muñoz ME, Arrieta M-C, Ramer-Tait AE, Walter J. A critical assessment of the "sterile womb" and "in utero colonization" hypotheses: implications for research on the pioneer infant microbiome. Microbiome. 2017;5(1):48.

[20] Kennedy KM, Gerlach MJ, Adam T, Heimesaat MM, Rossi L, Surette MG, Sloboda DM, Braun T. Fetal meconium does not have a detectable microbiota before birth. Nature Microbiology. 2021;6(7):865-73.

[21] Avershina E, Lundgård K, Sekelja M, Dotterud C, Storrø O, Øien T, Johnsen R, Rudi K. Transition from infantto adult-like gut microbiota. Environmental Microbiology. 2016;18(7):2226-36.

[22] Hill CJ, Lynch DB, Murphy K, Ulaszewska M, Jeffery IB, O'Shea CA, Watkins C, Dempsey E, Mattivi F, Tuohy K, Ross RP, Ryan CA, O' Toole PW, Stanton C. Evolution of gut microbiota composition from birth to 24 weeks in the INFANTMET Cohort. Microbiome. 2017;5(1):4.

[23] Favier CF, de Vos WM, Akkermans ADL. Development of bacterial and bifidobacterial communities in feces of newborn babies. Anaerobe. 2003;9(5):219-29.

[24] Del Chierico F, Vernocchi P, Petrucca A, Paci P, Fuentes S, Praticò G, Capuani G, Masotti A, Reddel S, Russo A, Vallone C, Salvatori G, Buffone E, Signore F, Rigon G, Dotta A, 
Miccheli A, de Vos WM, Dallapiccola B, Putignani L. Phylogenetic and Metabolic Tracking of Gut Microbiota during Perinatal Development. PloS one. 2015;10(9):e0137347-e.

[25] Koenig JE, Spor A, Scalfone N, Fricker AD, Stombaugh J, Knight R, Angenent LT, Ley RE. Succession of microbial consortia in the developing infant gut microbiome. Proceedings of the National Academy of Sciences. 2011; 108(Supplement 1):4578-85.

[26] de Muinck EJ, Trosvik P. Individuality and convergence of the infant gut microbiota during the first year of life. Nature Communications. 2018;9(1):2233.

[27] Palmer C, Bik EM, DiGiulio DB, Relman DA, Brown PO. Development of the Human Infant Intestinal Microbiota. PLOS Biology. 2007;5(7):e177.

[28] Bäckhed F, Roswall J, Peng Y, Feng Q, Jia H, KovatchevaDatchary P, Li Y, Xia Y, Xie H, Zhong H, Khan Muhammad T, Zhang J, Li J, Xiao L, Al-Aama J, Zhang D, Lee Ying S, Kotowska D, Colding C, Tremaroli V, Yin Y, Bergman S, Xu X, Madsen L, Kristiansen K, Dahlgren J, Wang J. Dynamics and Stabilization of the Human Gut Microbiome during the First Year of Life. Cell Host Microbe. 2015;17(5):690-703.

[29] Rodriguez JM, Murphy K, Stanton C, Ross RP, Kober OI, Juge N, Avershina E, Rudi K, Narbad A, Jenmalm MC, Marchesi JR, Collado MC. The composition of the gut microbiota throughout life, with an emphasis on early life. Microb Ecol Health Dis. 2015;26:26050.

[30] Hollister EB, Riehle K, Luna RA, Weidler EM, RubioGonzales M, Mistretta T-A, Raza S, Doddapaneni HV, Metcalf GA, Muzny DM, Gibbs RA, Petrosino JF, Shulman RJ, Versalovic J. Structure and function of the healthy pre-adolescent pediatric gut microbiome. Microbiome. 2015;3(1):36.

[31] Ringel-Kulka T, Cheng J, Ringel Y, Salojärvi J, Carroll I, Palva A, de Vos WM, Satokari R. Intestinal Microbiota in Healthy U.S. Young Children and Adults-A High Throughput Microarray Analysis. PLOS ONE. 2013;8(5): e64315.

[32] Cheng J, Ringel-Kulka T, Heikamp-de Jong I, Ringel Y, Carroll I, de Vos WM, Salojärvi J, Satokari R. Discordant temporal development of bacterial phyla and the emergence of core in the fecal microbiota of young children. The ISME Journal. 2016;10(4):1002-14.

[33] Zhong H, Penders J, Shi Z, Ren H, Cai K, Fang C, Ding Q, Thijs C, Blaak EE, Stehouwer CDA, Xu X, Yang H, Wang J, Wang J, Jonkers DMAE, Masclee AAM, Brix S, Li J, Arts ICW, Kristiansen K. Impact of early events and lifestyle on the gut microbiota and metabolic phenotypes in young school-age children. Microbiome. 2019;7(1):2.

[34] Guo M, Miao M, Wang Y, Duan M, Yang F, Chen Y, Yuan W, Zheng H. Developmental differences in the intestinal microbiota of Chinese 1-year-old infants and 4-year-old children. Scientific Reports. 2020;10(1):19470.

[35] Henderickx JGE, Zwittink RD, van Lingen RA, Knol J, Belzer C. The Preterm Gut Microbiota: An Inconspicuous Challenge in Nutritional Neonatal Care. Frontiers in Cellular and Infection Microbiology. 2019;9(85).

[36] Fouhy F, Watkins C, Hill CJ, O'Shea C-A, Nagle B, Dempsey EM, O’Toole PW, Ross RP, Ryan CA, Stanton C. Perinatal factors affect the gut microbiota up to four years after birth. Nature Communications. 2019;10(1):1517.

[37] Arboleya S, Binetti A, Salazar N, Fernández N, Solís G, Hernández-Barranco A, Margolles A, de los Reyes-Gavilán
CG, Gueimonde M. Establishment and development of intestinal microbiota in preterm neonates. FEMS Microbiology Ecology. 2012;79(3):763-72.

[38] Neu J. Necrotizing Enterocolitis: The Mystery Goes On. Neonatology. 2014;106(4):289-95.

[39] Zozaya C, García González I, Avila-Alvarez A, Oikonomopoulou N, Sánchez Tamayo T, Salguero E, Saenz de Pipaón M, García-Muñoz Rodrigo F, Couce ML. Incidence, Treatment, and Outcome Trends of Necrotizing Enterocolitis in Preterm Infants: A Multicenter Cohort Study. Frontiers in Pediatrics. 2020;8(188).

[40] Neu J. Gastrointestinal development and meeting the nutritional needs of premature infants. The American Journal of Clinical Nutrition. 2007;85(2):629S-34S.

[41] Kona SK, Matlock DN. Probiotics, Prebiotics, and Synbiotics for Preterm Neonates. NeoReviews. 2018;19(11): e654-e63.

[42] Chernikova DA, Madan JC, Housman ML, Zain-ul-abideen M, Lundgren SN, Morrison HG, Sogin ML, Williams SM, Moore JH, Karagas MR, Hoen AG. The premature infant gut microbiome during the first 6 weeks of life differs based on gestational maturity at birth. Pediatric Research. 2018;84(1):71-9.

[43] Schwiertz A, Gruhl B, Löbnitz M, Michel P, Radke M, Blaut M. Development of the Intestinal Bacterial Composition in Hospitalized Preterm Infants in Comparison with Breast-Fed, Full-Term Infants. Pediatric Research. 2003;54(3):393-9.

[44] La Rosa PS, Warner BB, Zhou Y, Weinstock GM, Sodergren E, Hall-Moore CM, Stevens HJ, Bennett WE, Jr., Shaikh N, Linneman LA, Hoffmann JA, Hamvas A, Deych E, Shands BA, Shannon WD, Tarr PI. Patterned progression of bacterial populations in the premature infant gut. Proc Natl Acad Sci U S A. 2014;111(34):12522-7.

[45] Korpela K, Blakstad EW, Moltu SJ, Strømmen K, Nakstad B, Rønnestad AE, Brække K, Iversen PO, Drevon CA, de Vos W. Intestinal microbiota development and gestational age in preterm neonates. Scientific Reports. 2018;8(1): 2453.

[46] Chang JY, Shin SM, Chun J, Lee J-H, Seo J-K. Pyrosequencing-based Molecular Monitoring of the Intestinal Bacterial Colonization in Preterm Infants. Journal of Pediatric Gastroenterology and Nutrition. 2011;53(5):512-9.

[47] Moles L, Gómez M, Jiménez E, Fernández L, Bustos G, Chaves F, Cantón R, Rodríguez JM, Del Campo R. Preterm infant gut colonization in the neonatal ICU and complete restoration 2 years later. Clin Microbiol Infect. 2015;21(10):936.e1-10.

[48] Jacquot A, Neveu D, Aujoulat F, Mercier G, Marchandin H, Jumas-Bilak E, Picaud J-C. Dynamics and Clinical Evolution of Bacterial Gut Microflora in Extremely Premature Patients. The Journal of Pediatrics. 2011;158(3):390-6.

[49] Parra-Llorca A, Gormaz M, Alcántara C, Cernada M, Nuñez-Ramiro A, Vento M, Collado MC. Preterm Gut Microbiome Depending on Feeding Type: Significance of Donor Human Milk. Front Microbiol. 2018;9:1376.

[50] Stewart CJ, Ajami NJ, O'Brien JL, Hutchinson DS, Smith DP, Wong MC, et al. Temporal development of the gut microbiome in early childhood from the TEDDY study. Nature. 2018;562(7728):583-8.

[51] Kuang Y-S, Li S-H, Guo Y, Lu J-H, He J-R, Luo B-J, Jiang F-J, Shen H, Papasian CJ, Pang H, Xia H-M, Deng H-W, Qiu 
X. Composition of gut microbiota in infants in China and global comparison. Scientific Reports. 2016;6(1):36666.

[52] Shao Y, Forster SC, Tsaliki E, Vervier K, Strang A, Simpson N, Kumar N, Stares MD, Rodger A, Brocklehurst P, Field N, Lawley TD. Stunted microbiota and opportunistic pathogen colonization in caesarean-section birth. Nature. 2019;574(7776):117-21.

[53] Rutayisire E, Huang K, Liu Y, Tao F. The mode of delivery affects the diversity and colonization pattern of the gut microbiota during the first year of infants' life: a systematic review. BMC Gastroenterol. 2016;16(1):86.

[54] Darabi B, Rahmati S, HafeziAhmadi MR, Badfar G, Azami M. The association between caesarean section and childhood asthma: an updated systematic review and meta-analysis. Allergy, Asthma \& Clinical Immunology. 2019;15(1):62.

[55] Thavagnanam S, Fleming J, Bromley A, Shields MD, Cardwell CR. A meta-analysis of the association between Caesarean section and childhood asthma. Clin Exp Allergy. 2008;38(4):629-33.

[56] Eggesbø M, Botten G, Stigum H, Nafstad P, Magnus P. Is delivery by cesarean section a risk factor for food allergy? J Allergy Clin Immunol. 2003;112(2):420-6.

[57] Blustein J, Attina T, Liu M, Ryan AM, Cox LM, Blaser MJ, Trasande L. Association of caesarean delivery with child adiposity from age 6 weeks to 15 years. Int J Obes (Lond). 2013;37(7):900-6.

[58] Cardwell CR, Stene LC, Joner G, Cinek O, Svensson J, Goldacre MJ, Parslow RC, Pozzilli P, Brigis G, Stoyanov D. Caesarean section is associated with an increased risk of childhood-onset type 1 diabetes mellitus: a metaanalysis of observational studies. Springer; Diabetologia. 2008;51(5):726-35.

[59] Martin R, Makino H, Cetinyurek Yavuz A, Ben-Amor K, Roelofs M, Ishikawa E, Kubota H, Swinkels S, Sakai T, Oishi K, Kushiro A, Knol J. Early-Life Events, Including Mode of Delivery and Type of Feeding, Siblings and Gender, Shape the Developing Gut Microbiota. PLoS One. 2016;11(6):e0158498.

[60] Nagpal R, Yamashiro Y. Gut Microbiota Composition in Healthy Japanese Infants and Young Adults Born by C-Section. Annals of Nutrition and Metabolism. 2018; 73(suppl 3)(3):4-11.

[61] Maynard CL, Elson CO, Hatton RD, Weaver CT. Reciprocal interactions of the intestinal microbiota and immune system. Nature. 2012;489(7415):231-41.

[62] Bokulich NA, Chung J, Battaglia T, Henderson N, Jay M, Li H, D Lieber A, Wu F, Perez-Perez GI, Chen Y, Schweizer W, Zheng X, Contreras M, Dominguez-Bello MG, Blaser MJ. Antibiotics, birth mode, and diet shape microbiome maturation during early life. Science translational medicine. 2016;8(343):343ra82-ra82.

[63] Morais LH, Golubeva AV, Moloney GM, Moya-Pérez A, Ventura-Silva AP, Arboleya S, Bastiaanssen TFS, O'Sullivan O, Rea K, Borre Y, Scott KA, Patterson E, Cherry P, Stilling R, Hoban AE, El Aidy S, Sequeira AM, Beers S, Moloney RD, Renes IB, Wang S, Knol J, Ross RP, O'Toole PW, Cotter PD, Stanton C, Dinan TG, Cryan JF. Enduring Behavioral Effects Induced by Birth by Caesarean Section in the Mouse. Curr Biol. 2020;30(19):3761-74.e6.

[64] Zwittink RD, Renes IB, van Lingen RA, van ZoerenGrobben D, Konstanti P, Norbruis OF, Martin R, Groot
Jebbink LJM, Knol J, Belzer C. Association between duration of intravenous antibiotic administration and early-life microbiota development in late-preterm infants. European Journal of Clinical Microbiology \& Infectious Diseases. 2018;37(3):475-83.

[65] Cox LM, Yamanishi S, Sohn J, Alekseyenko AV, Leung JM, Cho I, Kim SG, Li H, Gao Z, Mahana D, Zárate Rodriguez JG, Rogers AB, Robine N, Loke Pn, Blaser MJ. Altering the intestinal microbiota during a critical developmental window has lasting metabolic consequences. Cell. 2014;158(4):705-21.

[66] Mitre E, Susi A, Kropp LE, Schwartz DJ, Gorman GH, Nylund CM. Association Between Use of AcidSuppressive Medications and Antibiotics During Infancy and Allergic Diseases in Early Childhood. JAMA Pediatrics. 2018;172(6):e180315-e.

[67] Zhu WW, Li ZL. [Impact on the intestinal microbiota of early antibiotic treatment in preterm neonates]. Zhonghua Er Ke Za Zhi. 2018;56(7):505-10.

[68] Dardas M, Gill SR, Grier A, Pryhuber GS, Gill AL, Lee YH, Guillet R. The impact of postnatal antibiotics on the preterm intestinal microbiome. Pediatr Res. 2014;76(2):150-8.

[69] Fouhy F, Guinane CM, Hussey S, Wall R, Ryan CA, Dempsey EM, Murphy B, Ross RP, Fitzgerald GF, Stanton C, Cotter PD. High-throughput sequencing reveals the incomplete, short-term recovery of infant gut microbiota following parenteral antibiotic treatment with ampicillin and gentamicin. Antimicrobial Agents and Chemotherapy. 2012;56(11):5811-20.

[70] Lee JK-F, Hern Tan LT, Ramadas A, Ab Mutalib N-S, Lee LH. Exploring the Role of Gut Bacteria in Health and Disease in Preterm Neonates. International Journal of Environmental Research and Public Health. 2020;17(19):6963.

[71] Aloisio I, Mazzola G, Corvaglia LT, Tonti G, Faldella G, Biavati B, Di Gioia D. Influence of intrapartum antibiotic prophylaxis against group B Streptococcus on the early newborn gut composition and evaluation of the antiStreptococcus activity of Bifidobacterium strains. Applied Microbiology and Biotechnology. 2014;98(13):6051-60.

[72] Aloisio I, Quagliariello A, De Fanti S, Luiselli D, De Filippo C, Albanese D, Corvaglia LT, Faldella G, Di Gioia D. Evaluation of the effects of intrapartum antibiotic prophylaxis on newborn intestinal microbiota using a sequencing approach targeted to multi hypervariable $16 \mathrm{~S}$ rDNA regions. Applied Microbiology and Biotechnology. 2016;100(12):5537-46.

[73] Wandro S, Osborne S, Enriquez C, Bixby C, Arrieta A, Whiteson K. The Microbiome and Metabolome of Preterm Infant Stool Are Personalized and Not Driven by Health Outcomes, Including Necrotizing Enterocolitis and LateOnset Sepsis. mSphere. 2018;3(3):e00104-18.

[74] Neuman H, Forsythe P, Uzan A, Avni O, Koren O. Antibiotics in early life: dysbiosis and the damage done. FEMS Microbiology Reviews. 2018;42(4):489-99.

[75] Wang S, Ryan CA, Boyaval P, Dempsey EM, Ross RP, Stanton C. Maternal Vertical Transmission Affecting Early-life Microbiota Development. Trends Microbiol. 2020;28(1): 28-45.

[76] Crofts TS, Gasparrini AJ, Dantas G. Next-generation approaches to understand and combat the antibiotic resistome. Nature Reviews Microbiology. 2017;15(7):422-34.

[77] Gibson MK, Wang B, Ahmadi S, Burnham C-AD, Tarr PI, Warner BB, Dantas G. Developmental dynamics of 
the preterm infant gut microbiota and antibiotic resistome. Nature Microbiology. 2016;1(4):16024.

[78] Nogacka A, Salazar N, Suárez M, Milani C, Arboleya S, Solís G, Fernández N, Alaez L, Hernández-Barranco AM, de los Reyes-Gavilán CG, Ventura M, Gueimonde M. Impact of intrapartum antimicrobial prophylaxis upon the intestinal microbiota and the prevalence of antibiotic resistance genes in vaginally delivered full-term neonates. Microbiome. 2017;5(1):93.

[79] Tapiainen T, Koivusaari P, Brinkac L, Lorenzi HA, Salo J, Renko M, Pruikkonen H, Pokka T, Li W, Nelson K, Pirttilä AM, Tejesvi MV. Impact of intrapartum and postnatal antibiotics on the gut microbiome and emergence of antimicrobial resistance in infants. Scientific Reports. 2019;9(1):10635.

[80] Chong CYL, Bloomfield FH, O'Sullivan JM. Factors Affecting Gastrointestinal Microbiome Development in Neonates. Nutrients. 2018;10(3):274.

[81] Le Doare K, Holder B, Bassett A, Pannaraj PS. Mother's Milk: A Purposeful Contribution to the Development of the Infant Microbiota and Immunity. Frontiers in Immunology. 2018;9:361.

[82] Wang S, Egan M, Ryan CA, Boyaval P, Dempsey EM, Ross RP, Stanton C. A good start in life is importantperinatal factors dictate early microbiota development and longer term maturation. FEMS Microbiology Reviews. 2020;44(6):763-81.

[83] Horta BL, Bahl R, Martinés JC, Victora CG, World Health $\mathrm{O}$. Evidence on the long-term effects of breastfeeding : systematic review and meta-analyses. / Bernardo L. Horta... [et al.]. Geneva: World Health Organization; 2007.

[84] World Health Organization (2013) Short-term effects of breastfeeding: a systematic review on the benefits of breastfeeding on diarrhoea and pneumonia mortality. WHO Library Cataloguing-in-Publication Data. https://www. who.int/maternal_child_adolescent/documents/breast feeding_short_term_effects/en/ (accessed April 2021).

[85] Ballard O, Morrow AL. Human milk composition: nutrients and bioactive factors. Pediatr Clin North Am. 2013; 60(1):49-74.

[86] Gopalakrishna KP, Hand TW. Influence of Maternal Milk on the Neonatal Intestinal Microbiome. Nutrients. 2020;12(3):823.

[87] Musilova S, Rada V, Vlkova E, Bunesova V. Beneficial effects of human milk oligosaccharides on gut microbiota. Beneficial Microbes. 2014;5(3):273-83.

[88] Fernández L, Langa S, Martín V, Maldonado A, Jiménez E, Martín R, Rodríguez JM. The human milk microbiota: Origin and potential roles in health and disease. Pharmacological Research. 2013;69(1):1-10.

[89] Ruiz L, García-Carral C, Rodriguez JM. Unfolding the Human Milk Microbiome Landscape in the Omics Era. Frontiers in Microbiology. 2019;10(1378).

[90] Kim SY, Yi DY. Analysis of the human breast milk microbiome and bacterial extracellular vesicles in healthy mothers. Experimental \& Molecular Medicine. 2020;52(8): 1288-97.

[91] Timmerman HM, Rutten NBMM, Boekhorst J, Saulnier DM, Kortman GAM, Contractor N, Kullen M, Floris E, Harmsen HJM, Vlieger AM, Kleerebezem M, Rijkers GT. Intestinal colonisation patterns in breastfed and formula-fed infants during the first 12 weeks of life reveal sequential microbiota signatures. Scientific Reports. 2017;7(1): 8327.

[92] Murphy K, Curley D, O'Callaghan TF, O'Shea CA, Dempsey EM, O'Toole PW, Ross RP, Ryan CA, Stanton C. The Composition of Human Milk and Infant Faecal Microbiota Over the First Three Months of Life: A Pilot Study. Sci Rep. 2017;7:40597.

[93] Ahern GJ, Hennessy AA, Ryan CA, Ross RP, Stanton C. Advances in Infant Formula Science. Annual Review of Food Science and Technology. 2019;10(1):75-102.

[94] Le Huërou-Luron I, Blat S, Boudry G. Breast- v. formulafeeding: impacts on the digestive tract and immediate and long-term health effects. Nutr Res Rev. 2010;23(1):23-36.

[95] Stark PL, Lee A. The Microbial Ecology of the Large Bowel of Breastfed and Formula-fed Infants During the First Year of Life. Journal of Medical Microbiology. 1982;15(2): 189-203.

[96] Bezirtzoglou E, Tsiotsias A, Welling GW. Microbiota profile in feces of breast- and formula-fed newborns by using fluorescence in situ hybridization (FISH). Anaerobe. 2011;17(6):478-82.

[97] Ma J, Li Z, Zhang W, Zhang C, Zhang Y, Mei H, Zhuo N, Wang $\mathrm{H}$, Wang $\mathrm{L}, \mathrm{Wu} \mathrm{D}$. Comparison of gut microbiota in exclusively breast-fed and formula-fed babies: a study of 91 term infants. Scientific Reports. 2020;10(1):15792.

[98] Beijers R, Buitelaar JK, de Weerth C. Mechanisms underlying the effects of prenatal psychosocial stress on child outcomes: beyond the HPA axis. European Child \& Adolescent Psychiatry. 2014;23(10):943-56.

[99] Austin M-P, Leader L. Maternal stress and obstetric and infant outcomes: epidemiological findings and neuroendocrine mechanisms. Australian and New Zealand Journal of Obstetrics and Gynaecology. 2000;40(3):331-7.

[100] Mulder EJH, Robles de Medina PG, Huizink AC, Van den Bergh BRH, Buitelaar JK, Visser GHA. Prenatal maternal stress: effects on pregnancy and the (unborn) child. Early Human Development. 2002;70(1):3-14.

[101] Entringer S. Impact of stress and stress physiology during pregnancy on child metabolic function and obesity risk. Curr Opin Clin Nutr Metab Care. 2013;16(3):320-7.

[102] Zijlmans MAC, Korpela K, Riksen-Walraven JM, de Vos WM, de Weerth C. Maternal prenatal stress is associated with the infant intestinal microbiota. Psychoneuroendocrinology. 2015;53:233-45.

[103] Zijlmans MAC, Beijers R, Riksen-Walraven MJ, de Weerth C. Maternal late pregnancy anxiety and stress is associated with children's health: a longitudinal study. Stress. 2017;20(5):495-504.

[104] Aatsinki A-K, Keskitalo A, Laitinen V, Munukka E, Uusitupa H-M, Lahti L, Kortesluoma S, Mustonen P, Rodrigues AJ, Coimbra B, Huovinen P, Karlsson H, Karlsson L. Maternal prenatal psychological distress and hair cortisol levels associate with infant fecal microbiota composition at 2.5 months of age. Psychoneuroendocrinology. 2020;119:104754.

[105] Naudé PJW, Claassen-Weitz S, Gardner-Lubbe S, Botha G, Kaba M, Zar HJ, Nicol MP, Stein DJ. Association of maternal prenatal psychological stressors and distress with maternal and early infant faecal bacterial profile. Acta Neuropsychiatrica. 2020;32(1):32-42.

[106] Huang T-T, Lai J-B, Du Y-L, Xu Y, Ruan L-M, Hu S-H. Current Understanding of Gut Microbiota in Mood 
Disorders: An Update of Human Studies. Front Genet. 2019;10:98.

[107] Bailey MT, Lubach GR, Coe CL. Prenatal Stress Alters Bacterial Colonization of the Gut in Infant Monkeys. Journal of Pediatric Gastroenterology and Nutrition. 2004;38(4): 414-21.

[108] Kelly JR, Kennedy PJ, Cryan JF, Dinan TG, Clarke G, Hyland NP. Breaking down the barriers: the gut microbiome, intestinal permeability and stress-related psychiatric disorders. Front Cell Neurosci. 2015;9:392.

[109] O'Mahony SM, Clarke G, Dinan TG, Cryan JF. Early-life adversity and brain development: Is the microbiome a missing piece of the puzzle? Neuroscience. 2017;342:37-54.

[110] Jašarević E, Howerton CL, Howard CD, Bale TL. Alterations in the Vaginal Microbiome by Maternal Stress Are Associated With Metabolic Reprogramming of the Offspring Gut and Brain. Endocrinology. 2015;156(9): 3265-76.

[111] Jašarević E, Howard CD, Misic AM, Beiting DP, Bale TL. Stress during pregnancy alters temporal and spatial dynamics of the maternal and offspring microbiome in a sex-specific manner. Scientific Reports. 2017;7(1):44182.

[112] Beydoun H, Saftlas AF. Physical and mental health outcomes of prenatal maternal stress in human and animal studies: a review of recent evidence. Paediatric and Perinatal Epidemiology. 2008;22(5):438-66.

[113] Zhuang L, Chen H, Zhang S, Zhuang J, Li Q, Feng Z. Intestinal Microbiota in Early Life and Its Implications on Childhood Health. Genomics, Proteomics \& Bioinformatics. 2019;17(1):13-25.

[114] Bisgaard H, Li N, Bonnelykke K, Chawes BLK, Skov T, Paludan-Müller G, Stokholm J, Smith B, Krogfelt KA. Reduced diversity of the intestinal microbiota during infancy is associated with increased risk of allergic disease at school age. Journal of Allergy and Clinical Immunology. 2011;128(3):646-52.e5.

[115] Azad MB, Konya T, Guttman DS, Field CJ, Sears MR, HayGlass KT, Mandhane PJ, Turvey SE, Subbarao P, Becker AB, Scott JA, Kozyrskyj AL. Infant gut microbiota and food sensitization: associations in the first year of life. Clin Exp Allergy. 2015;45(3):632-43.

[116] Chen CC, Chen KJ, Kong MS, Chang HJ, Huang JL. Alterations in the gut microbiotas of children with food sensitization in early life. Pediatr Allergy Immunol. 2016;27(3):254-62.

[117] Łoś-Rycharska E, GoŁębiewski M, Grzybowski T, Rogalla-Ładniak U, Krogulska A. The microbiome and its impact on food allergy and atopic dermatitis in children. Postepy Dermatol Alergol. 2020;37(5):641-50.

[118] Reddel S, Del Chierico F, Quagliariello A, Giancristoforo S, Vernocchi P, Russo A, Fiocchi A, Rossi P, Putignani L, El Hachem M. Gut microbiota profile in children affected by atopic dermatitis and evaluation of intestinal persistence of a probiotic mixture. Scientific Reports. 2019;9(1):4996.

[119] Huang R, Ning H, Shen M, Li J, Zhang J, Chen X. Probiotics for the Treatment of Atopic Dermatitis in Children: A Systematic Review and Meta-Analysis of Randomized Controlled Trials. Frontiers in Cellular and Infection Microbiology. 2017;7:392.

[120] Prakoeswa CRS, Herwanto N, Prameswari R, Astari L, Sawitri S, Hidayati AN, et al. Lactobacillus plantarum IS-10506 supplementation reduced SCORAD in children with atopic dermatitis. Beneficial Microbes. 2017;8(5): 833-40.

[121] van Nimwegen FA, Penders J, Stobberingh EE, Postma DS, Koppelman GH, Kerkhof M, Reijmerink NE, Dompeling E, van den Brandt PA, Ferreira I, Mommers M, Thijs C. Mode and place of delivery, gastrointestinal microbiota, and their influence on asthma and atopy. Journal of Allergy and Clinical Immunology. 2011;128(5):948-55.e3.

[122] Elazab N, Mendy A, Gasana J, Vieira ER, Quizon A, Forno E. Probiotic Administration in Early Life, Atopy, and Asthma: A Meta-analysis of Clinical Trials. Pediatrics. 2013;132(3):e666-e76.

[123] Goran MI, Ball GDC, Cruz ML. Obesity and Risk of Type 2 Diabetes and Cardiovascular Disease in Children and Adolescents. The Journal of Clinical Endocrinology \& Metabolism. 2003;88(4):1417-27.

[124] Scheepers LEJM, Penders J, Mbakwa CA, Thijs C, Mommers M, Arts ICW. The intestinal microbiota composition and weight development in children: the KOALA Birth Cohort Study. International Journal of Obesity. 2015;39(1):16-25.

[125] Li Y-F, Lin S-J, Chiang T-1. Timing of rapid weight gain and its effect on subsequent overweight or obesity in childhood: findings from a longitudinal birth cohort study. BMC Pediatrics. 2020;20(1):293.

[126] Ley RE, Bäckhed F, Turnbaugh P, Lozupone CA, Knight RD, Gordon JI. Obesity alters gut microbial ecology. Proceedings of the National Academy of Sciences of the United States of America. 2005;102(31):11070-5.

[127] Turnbaugh PJ, Ley RE, Mahowald MA, Magrini V, Mardis ER, Gordon JI. An obesity-associated gut microbiome with increased capacity for energy harvest. Nature. 2006;444(7122):1027-31.

[128] Abdallah Ismail N, Ragab SH, Abd Elbaky A, Shoeib ARS, Alhosary Y, Fekry D. Frequency of Firmicutes and Bacteroidetes in gut microbiota in obese and normal weight Egyptian children and adults. Arch Med Sci. 2011;7(3):501-7.

[129] Duncan SH, Lobley GE, Holtrop G, Ince J, Johnstone AM, Louis P, Flint HJ. Human colonic microbiota associated with diet, obesity and weight loss. International Journal of Obesity. 2008;32(11):1720-4.

[130] Zhang H, DiBaise JK, Zuccolo A, Kudrna D, Braidotti M, Yu Y, Parameswaran P, Crowell MD, Wing R, Rittmann BE, Krajmalnik-Brown R. Human gut microbiota in obesity and after gastric bypass. Proceedings of the National Academy of Sciences. 2009;106(7):2365-70.

[131] Gao X, Jia R, Xie L, Kuang L, Feng L, Wan C. Obesity in school-aged children and its correlation with Gut E.coli and Bifidobacteria: a case-control study. BMC Pediatrics. 2015;15(1):64.

[132] Petraroli M, Castellone E, Patianna V, Esposito S. Gut Microbiota and Obesity in Adults and Children: The State of the Art. Frontiers in Pediatrics. 2021;9:657020.

[133] Karvonen AM, Sordillo JE, Gold DR, Bacharier LB, O'Connor GT, Zeiger RS, Beigelman A, Weiss ST, Litonjua AA. Gut microbiota and overweight in 3-year old children. International Journal of Obesity. 2019;43(4): 713-23.

[134] Sugino K, Comstock S, Paneth N. The Infant Gut Microbiota at 12 Months and Its Associations with Maternal Pre-pregnancy BMI, Human Milk Exposure and Infant 
BMI-for-age Z-score (OR01-05-19). Current Developments in Nutrition. 2019;3(Supplement_1).

[135] Costa N, Santos P, Ferreira A, Williams B, Figueiredo A, Princisval L, Batalha M, Knoop M, Kac G, CoutoRodriguez M, Guo C. Maternal Pre-Pregnancy Body Mass Index and Gestational Weight Gain Are Associated with Differences in Infant Gut Microbiota: Results from Brazilian Prospective Birth Cohort. Current Developments in Nutrition. 2020;4(Supplement_2):1551.

[136] Singh SB, Madan J, Coker M, Hoen A, Baker ER, Karagas MR, Mueller NT. Does birth mode modify associations of maternal pre-pregnancy BMI and gestational weight gain with the infant gut microbiome? International Journal of Obesity (2005). 2020;44(1):23-32.

[137] Butte NF. The Role of Breastfeeding in Obesity. Pediatr Clin North Am. 2001;48(1):189-98.

[138] Soderborg TK, Borengasser SJ, Barbour LA, Friedman JE. Microbial transmission from mothers with obesity or diabetes to infants: an innovative opportunity to interrupt a vicious cycle. Diabetologia. 2016;59(5):895-906.

[139] Mesquita DN, Barbieri MA, Goldani HAS, Cardoso VC, Goldani MZ, Kac G, Silva AAM, Bettiol H. Cesarean Section Is Associated with Increased Peripheral and Central Adiposity in Young Adulthood: Cohort Study. PLOS ONE. 2013;8(6):e66827.

[140] Dawson-Hahn EE, Rhee KE. The association between antibiotics in the first year of life and child growth trajectory. BMC Pediatrics. 2019;19(1):23.

[141] Gerber JS, Bryan M, Ross RK, Daymont C, Parks EP, Localio AR, Grundmeier RW, Stallings VA, Zaoutis TE. Antibiotic Exposure During the First 6 Months of Life and Weight Gain During Childhood. JAMA. 2016;315(12): 1258-65.

[142] Kelly D, Kelly A, O’Dowd T, Hayes CB. Antibiotic use in early childhood and risk of obesity: longitudinal analysis of a national cohort. World J Pediatr. 2019;15(4):390-7.

[143] Azad MB, Bridgman SL, Becker AB, Kozyrskyj AL. Infant antibiotic exposure and the development of childhood overweight and central adiposity. International Journal of Obesity. 2014;38(10):1290-8.

[144] Chen L-W, Xu J, Soh SE, Aris IM, Tint M-T, Gluckman PD, Tan KH, Shek LP-C, Chong Y-S, Yap F, Godfrey KM, Gilbert JA, Karnani N, Lee YS. Implication of gut microbiota in the association between infant antibiotic exposure and childhood obesity and adiposity accumulation. International Journal of Obesity. 2020;44(7):1508-20.

[145] Grenham S, Clarke G, Cryan J, Dinan T. Brain-GutMicrobe Communication in Health and Disease. Frontiers in Physiology. 2011;2(94).

[146] O'Mahony SM, Hyland NP, Dinan TG, Cryan JF. Maternal separation as a model of brain-gut axis dysfunction. Psychopharmacology. 2011;214(1):71-88.

[147] Jena A, Montoya CA, Mullaney JA, Dilger RN, Young W, McNabb WC, Roy NC. Gut-Brain Axis in the Early Postnatal Years of Life: A Developmental Perspective. Frontiers in Integrative Neuroscience. 2020;14(44).

[148] Carabotti M, Scirocco A, Maselli MA, Severi C. The gut-brain axis: interactions between enteric microbiota, central and enteric nervous systems. Ann Gastroenterol. 2015;28(2):203-9.

[149] Toral M, Robles-Vera I, de la Visitación N, Romero M, Yang T, Sánchez M, Gómez-Guzmán M, Jiménez R, Raizada
MK, Duarte J. Critical Role of the Interaction Gut Microbiota - Sympathetic Nervous System in the Regulation of Blood Pressure. Frontiers in Physiology. 2019;10(231).

[150] Mayer EA, Tillisch K, Gupta A. Gut/brain axis and the microbiota. The Journal of Clinical Investigation. 2015; 125(3):926-38.

[151] Farzi A, Fröhlich EE, Holzer P. Gut Microbiota and the Neuroendocrine System. Neurotherapeutics. 2018;15(1): $5-22$.

[152] Huo R, Zeng B, Zeng L, Cheng K, Li B, Luo Y, Wang H, Zhou C, Fang L, Li W, Niu R, Wei H, Xie P. Microbiota Modulate Anxiety-Like Behavior and Endocrine Abnormalities in Hypothalamic-Pituitary-Adrenal Axis. Frontiers in Cellular and Infection Microbiology. 2017; 7(489).

[153] Wenner MM. Sympathetic activation in chronic anxiety: not just at the "height" of stress. Editorial Focus on "Relative burst amplitude of muscle sympathetic nerve activity is an indicator of altered sympathetic outflow in chronic anxiety". Journal of Neurophysiology. 2018;120(1):7-8.

[154] Christian LM, Galley JD, Hade EM, Schoppe-Sullivan S, Kamp Dush C, Bailey MT. Gut microbiome composition is associated with temperament during early childhood. Brain Behav Immun. 2015;45:118-27.

[155] Carlson AL, Xia K, Azcarate-Peril MA, Goldman BD, Ahn M, Styner MA, Thompson AL, Geng X, Gilmore JH, Knickmeyer RC. Infant Gut Microbiome Associated With Cognitive Development. Biol Psychiatry. 2018;83(2): 148-59.

[156] Wang LJ, Yang CY, Chou WJ, Lee MJ, Chou MC, Kuo HC, Yeh YM, Lee SY, Huang LH, Li SC. Gut microbiota and dietary patterns in children with attention-deficit/ hyperactivity disorder. Eur Child Adolesc Psychiatry. 2020;29(3):287-97.

[157] Dinan TG, Borre YE, Cryan JF. Genomics of schizophrenia: time to consider the gut microbiome? Molecular Psychiatry. 2014;19(12):1252-7.

[158] Zhu F, Ju Y, Wang W, Wang Q, Guo R, Ma Q, Sun Q, Fan Y, Xie Y, Yang Z, Jie Z, Zhao B, Xiao L, Yang L, Zhang T, Feng J, Guo L, He X, Chen Y, Chen C, Gao C, Xu X, Yang H, Wang J, Dang Y, Madsen L, Brix S, Kristiansen K, Jia H, Ma X. Metagenome-wide association of gut microbiome features for schizophrenia. Nature Communications. 2020;11(1):1612.

[159] Tomova A, Husarova V, Lakatosova S, Bakos J, Vlkova B, Babinska K, Ostatnikova D. Gastrointestinal microbiota in children with autism in Slovakia. Physiology \& Behavior. 2015;138:179-87.

[160] Finegold SM, Dowd SE, Gontcharova V, Liu C, Henley KE, Wolcott RD, Youn E, Summanen PH, Granpeesheh D, Dixon D, Liu M, Molitoris DR, Green JA. Pyrosequencing study of fecal microflora of autistic and control children. Anaerobe. 2010;16(4):444-53.

[161] Iglesias-Vázquez L, Van Ginkel Riba G, Arija V, Canals J. Composition of Gut Microbiota in Children with Autism Spectrum Disorder: A Systematic Review and MetaAnalysis. Nutrients. 2020;12(3):792.

[162] Crumeyrolle-Arias M, Jaglin M, Bruneau A, Vancassel S, Cardona A, Daugé V, Naudon L, Rabot S. Absence of the gut microbiota enhances anxiety-like behavior and neuroendocrine response to acute stress in rats. Psychoneuroendocrinology. 2014;42:207-17. 
[163] Neufeld KA, Kang N, Bienenstock J, Foster JA. Effects of intestinal microbiota on anxiety-like behavior. Commun Integr Biol. 2011;4(4):492-4.

[164] Faith JJ, Guruge JL, Charbonneau M, Subramanian S, Seedorf H, Goodman AL, Clemente JC, Knight R, Heath AC, Leibel RL, Rosenbaum M, Gordon JI. The long-term stability of the human gut microbiota. Science. 2013; 341(6141): 1237439.

[165] Salazar N, González S, Nogacka AM, Rios-Covián D, Arboleya S, Gueimonde M, Reyes-Gavilán CGL. Microbiome: Effects of Ageing and Diet. Curr Issues Mol Biol. 2020;36:33-62.

[166] Biagi E, Rampelli S, Turroni S, Quercia S, Candela M, Brigidi P. The gut microbiota of centenarians: Signatures of longevity in the gut microbiota profile. Mech Ageing Dev. 2017;165(Pt B):180-4.

[167] Salazar N, López P, Valdés L, Margolles A, Suárez A, Patterson AM, Cuervo A, de los Reyes-Gavilán CG, RuasMadiedo P, Gonzalez S, Gueimonde M. Microbial targets for the development of functional foods accordingly with nutritional and immune parameters altered in the elderly. $\mathrm{J}$ Am Coll Nutr. 2013;32(6):399-406.

[168] Salazar N, Arboleya S, Valdés L, Stanton C, Ross P, Ruiz L, Gueimonde M, de Los Reyes-Gavilán CG. The human intestinal microbiome at extreme ages of life. Dietary intervention as a way to counteract alterations. Front Genet. 2014;5:406.

[169] Mariat D, Firmesse O, Levenez F, Guimarăes V, Sokol H, Doré J, Corthier G, Furet JP. The Firmicutes/Bacteroidetes ratio of the human microbiota changes with age. BMC Microbiol. 2009;9:123.

[170] Claesson MJ, Cusack S, O’Sullivan O, Greene-Diniz R, de Weerd H, Flannery E, Marchesi JR, Falush D, Dinan T, Fitzgerald G, Stanton C, van Sinderen D, O'Connor M, Harnedy N, O'Connor K, Henry C, O'Mahony D, Fitzgerald AP, Shanahan F, Twomey C, Hill C, Ross RP, O'Toole PW. Composition, variability, and temporal stability of the intestinal microbiota of the elderly. Proc Natl Acad Sci U S A. 2011;108 Suppl 1(Suppl 1):4586-91.

[171] Biagi E, Nylund L, Candela M, Ostan R, Bucci L, Pini E, Nikkila J, Monti D, Satokari R, Franceschi C, Brigidi P, De Vos W. Through ageing, and beyond: gut microbiota and inflammatory status in seniors and centenarians. PLoS One. 2010;5(5):e10667.

[172] Claesson MJ, Jeffery IB, Conde S, Power SE, O'Connor EM, Cusack S, Harris HM, Coakley M, Lakshminarayanan B, O’Sullivan O, Fitzgerald GF, Deane J, O'Connor M, Harnedy N, O'Connor K, O'Mahony D, van Sinderen D, Wallace M, Brennan L, Stanton C, Marchesi JR, Fitzgerald AP, Shanahan F, Hill C, Ross RP, O'Toole PW. Gut microbiota composition correlates with diet and health in the elderly. Nature. 2012;488(7410):178-84.

[173] Odamaki T, Kato K, Sugahara H, Hashikura N, Takahashi S, Xiao JZ, Abe F, Osawa R. Age-related changes in gut microbiota composition from newborn to centenarian: a cross-sectional study. BMC Microbiol. 2016; 16:90.

[174] Gavini F, Cayuela Ch, Antoine JM, Lecoq C, Lefebvre B, Membré JM, Neut, C. Differences in the distribution of bifidobacterial and enterobacterial species in human faecal microflora of three different (children, adults, elderly) age groups. Microb Ecol Health Dis.2001;13:40-45.
[175] Hopkins MJ, Sharp R, Macfarlane GT. Age and disease related changes in intestinal bacterial populations assessed by cell culture, $16 \mathrm{~S}$ rRNA abundance, and community cellular fatty acid profiles. Gut. 2001;48(2):198-205.

[176] Mueller S, Saunier K, Hanisch C, Norin E, Alm L, Midtvedt T, Cresci A, Silvi S, Orpianesi C, Verdenelli MC, Clavel T, Koebnick C, Zunft HJ, Doré J, Blaut M. Differences in fecal microbiota in different European study populations in relation to age, gender, and country: a cross-sectional study. Appl Environ Microbiol. 2006;72(2):1027-33.

[177] Zwielehner J, Liszt K, Handschur M, Lassl C, Lapin A, Haslberger AG. Combined PCR-DGGE fingerprinting and quantitative-PCR indicates shifts in fecal population sizes and diversity of Bacteroides, bifidobacteria and Clostridium cluster IV in institutionalized elderly. Exp Gerontol. 2009;44(6-7):440-6.

[178] Mäkivuokko H, Tiihonen K, Tynkkynen S, Paulin L, Rautonen N. The effect of age and non-steroidal anti-inflammatory drugs on human intestinal microbiota composition. Br J Nutr. 2010;103(2):227-34.

[179] Woodmansey EJ, McMurdo ME, Macfarlane GT, Macfarlane S. Comparison of compositions and metabolic activities of fecal microbiotas in young adults and in antibiotic-treated and non-antibiotic-treated elderly subjects. Appl Environ Microbiol. 2004;70(10):6113-22.

[180] Lovat LB. Age related changes in gut physiology and nutritional status. Gut. 1996;38(3):306-9.

[181] Ticinesi A, Milani C, Lauretani F, Nouvenne A, Mancabelli L, Lugli GA, Turroni F, Duranti S, Mangifesta M, Viappiani A, Ferrario C, Maggio M, Ventura M, Meschi T. Gut microbiota composition is associated with polypharmacy in elderly hospitalized patients. Sci Rep. 2017;7(1):11102.

[182] Biagi E, Candela M, Fairweather-Tait S, Franceschi C, Brigidi P. Aging of the human metaorganism: the microbial counterpart. Age (Dordr). 2012;34(1):247-67.

[183] Jackson MA, Jeffery IB, Beaumont M, Bell JT, Clark AG, Ley RE, O'Toole PW, Spector TD, Steves CJ. Signatures of early frailty in the gut microbiota. Genome Med. 2016;8(1):8. doi: 10.1186/s13073-016-0262-7. Erratum in: Genome Med. 2016;8(1):21. Jackson, Matt [corrected to Jackson, Matthew A]. PMID: 26822992; PMCID: PMC4731918.

[184] Haran JP, Bucci V, Dutta P, Ward D, McCormick B. The nursing home elder microbiome stability and associations with age, frailty, nutrition and physical location. J Med Microbiol. 2018;67(1):40-51.

[185] Haran JP, Ward DV, Bhattarai SK, Loew E, Dutta P, Higgins A, McCormick BA, Bucci V. The high prevalence of Clostridioides difficile among nursing home elders associates with a dysbiotic microbiome. Gut Microbes. 2021;13(1):1-15.

[186] Jump RLP. Clostridium difficile infection in older adults. Aging Health 2013;9:403-14

[187] Rea MC, O'Sullivan O, Shanahan F, O'Toole PW, Stanton C, Ross RP, Hill C. Clostridium difficile carriage in elderly subjects and associated changes in the intestinal microbiota. J Clin Microbiol. 2012;50(3):867-75.

[188] Theriot CM, Koenigsknecht MJ, Carlson PE, Jr, Hatton GE, Nelson AM, Li B, Huffnagle GB, Z Li J, Young VB. Antibiotic-induced shifts in the mouse gut microbiome and metabolome increase susceptibility to Clostridium difficile infection. Nat Commun. 2014;5:3114. 
[189] Milani C, Ticinesi A, Gerritsen J, Nouvenne A, Lugli GA, Mancabelli L, Turroni F, Duranti S, Mangifesta M, Viappiani A, Ferrario C, Maggio M, Lauretani F, De Vos W, van Sinderen D, Meschi T, Ventura M. Gut microbiota composition and Clostridium difficile infection in hospitalized elderly individuals: a metagenomic study. Sci Rep. 2016;6:25945.

[190] Franceschi C, Garagnani P, Parini P, Giuliani C, Santoro A. Inflammaging: a new immune-metabolic viewpoint for agerelated diseases. Nat Rev Endocrinol. 2018;14(10):576-90.

[191] Ferrucci L, Fabbri E. Inflammageing: chronic inflammation in ageing, cardiovascular disease, and frailty. Nat Rev Cardiol. 2018;15(9):505-22.

[192] Zheng D, Liwinski T, Elinav E. Interaction between microbiota and immunity in health and disease. Cell Res. 2020;30(6):492-506.

[193] Fransen F, van Beek AA, Borghuis T, Aidy SE, Hugenholtz F, van der Gaast-de Jongh C, Savelkoul HFJ, De Jonge MI, Boekschoten MV, Smidt H, Faas MM, de Vos P. Aged Gut Microbiota Contributes to Systemical Inflammaging after Transfer to Germ-Free Mice. Front Immunol. 2017; $8: 1385$.

[194] Salazar N, Arboleya S, Fernández-Navarro T, de Los ReyesGavilán CG, Gonzalez S, Gueimonde M. Age-Associated Changes in Gut Microbiota and Dietary Components Related with the Immune System in Adulthood and Old Age: A Cross-Sectional Study. Nutrients. 2019;11(8):1765.

[195] Sun M, Wu W, Chen L, Yang W, Huang X, Ma C, Chen F, Xiao Y, Zhao Y, Ma C, Yao S, Carpio VH, Dann SM, Zhao Q, Liu Z, Cong Y. Microbiota-derived short-chain fatty acids promote Th1 cell IL-10 production to maintain intestinal homeostasis. Nat Commun. 2018;9(1):3555.

[196] Magnusson MK, Isaksson S, Öhman L. The antiinflammatory immune regulation induced by butyrate is impaired in inflamed intestinal mucosa from patients with ulcerative colitis. Inflammation. 2020;43(2):507-17.

[197] Tran L, Greenwood-Van Meerveld B. Age-associated remodeling of the intestinal epithelial barrier. J Gerontol A Biol Sci Med Sci. 2013;68(9):1045-56.

[198] Kim KA, Jeong JJ, Yoo, SY, Kim DH. Gut Microbiota lipopolysaccharide accelerates inflamm-aging in mice. BMC Microbiol. 2016;16:9.

[199] Morais LH, Schreiber HL, 4th, Mazmanian SK. The gut microbiota-brain axis in behaviour and brain disorders. Nat Rev Microbiol. 2021;19(4):241-55. doi: 10.1038/s41579020-00460-0. Epub 2020 Oct 22. PMID: 33093662.

[200] Cryan JF, O'Riordan KJ, Cowan CSM, Sandhu KV, Bastiaanssen TFS, Boehme M, Codagnone MG, Cussotto S, Fulling C, Golubeva AV, Guzzetta KE, Jaggar M, Long-Smith CM, Lyte JM, Martin JA, Molinero-Perez A, Moloney G, Morelli E, Morillas E, O’Connor R, CruzPereira JS, Peterson VL, Rea K, Ritz NL, Sherwin E, Spichak S, Teichman EM, van de Wouw M, Ventura-Silva AP, Wallace-Fitzsimons SE, Hyland N, Clarke G, Dinan TG. The Microbiota-Gut-Brain Axis. Physiol Rev. 2019; 99(4):1877-2013.

[201] Barrett E, Ross RP, O’Toole PW, Fitzgerald GF, Stanton C. $\gamma$-Aminobutyric acid production by culturable bacteria from the human intestine. J Appl Microbiol. 2012;113(2):411-7.

[202] Yano JM, Yu K, Donaldson GP, Shastri GG, Ann P, Ma L, Nagler CR, Ismagilov RF, Mazmanian SK, Hsiao EY.
Indigenous bacteria from the gut microbiota regulate host serotonin biosynthesis. Cell. 2015;161(2):264-76.

[203] Dalile B, Van Oudenhove L, Vervliet B, Verbeke K. The role of short-chain fatty acids in microbiota-gut-brain communication. Nat Rev Gastroenterol Hepatol. 2019;16(8): 461-78.

[204] van de Wouw M, Boehme M, Lyte JM, Wiley N, Strain C, O'Sullivan O, Clarke G, Stanton C, Dinan TG, Cryan JF. Short-chain fatty acids: microbial metabolites that alleviate stress-induced brain-gut axis alterations. J Physiol. 2018;596(20):4923-44.

[205] Cryan JF, O'Riordan KJ, Sandhu K, Peterson V, Dinan TG. The gut microbiome in neurological disorders. Lancet Neurol. 2020;19(2):179-94.

[206] Kesika P, Suganthy N, Sivamaruthi BS, Chaiyasut C. Role of gut-brain axis, gut microbial composition, and probiotic intervention in Alzheimer's disease. Life Sci. 2021;264:118627.

[207] Kumar DK, Choi SH, Washicosky KJ, Eimer WA, Tucker S, Ghofrani J, Lefkowitz A, McColl G, Goldstein LE, Tanzi $\mathrm{RE}$, Moir RD. Amyloid- $\beta$ peptide protects against microbial infection in mouse and worm models of Alzheimer's disease. Sci Transl Med. 2016;8(340):340ra72.

[208] Cattaneo A, Cattane N, Galluzzi S, Provasi S, Lopizzo N, Festari C, Ferrari C, Guerra UP, Paghera B, Muscio C, Bianchetti A, Volta GD, Turla M, Cotelli MS, Gennuso M, Prelle A, Zanetti O, Lussignoli G, Mirabile D, Bellandi D, Gentile S, Belotti G, Villani D, Harach T, Bolmont T, Padovani A, Boccardi M, Frisoni GB; INDIA-FBP Group. Association of brain amyloidosis with pro-inflammatory gut bacterial taxa and peripheral inflammation markers in cognitively impaired elderly. Neurobiol Aging. 2017;49:60-68.

[209] Kim MS, Kim Y, Choi H, Kim W, Park S, Lee D, Kim DK, Kim HJ, Choi H, Hyun DW, Lee JY, Choi EY, Lee DS, Bae JW, Mook-Jung I. Transfer of a healthy microbiota reduces amyloid and tau pathology in an Alzheimer's disease animal model. Gut. 2020;69(2):283-294.

[210] Mulak A, Bonaz B. Brain-gut-microbiota axis in Parkinson's disease. World J Gastroenterol. 2015;21(37): 10609-20.

[211] Edwards LL, Quigley EM, Pfeiffer RF. Gastrointestinal dysfunction in Parkinson's disease: frequency and pathophysiology. Neurology. 1992;42(4):726-32.

[212] Mertsalmi TH, Aho VTE, Pereira PAB, Paulin L, Pekkonen E, Auvinen P, Scheperjans F. More than constipation bowel symptoms in Parkinson's disease and their connection to gut microbiota. Eur J Neurol. 2017;24(11):1375-83.

[213] Devos D, Lebouvier T, Lardeux B, Biraud M, Rouaud T, Pouclet H, Coron E, Bruley des Varannes S, Naveilhan P, Nguyen JM, Neunlist M, Derkinderen P. Colonic inflammation in Parkinson's disease. Neurobiol Dis. 2013;50:42-8.

[214] Olanow CW, Wakeman DR, Kordower JH. Peripheral alphasynuclein and Parkinson's disease. Mov Disord. 2014;29:963-6

[215] Pfeiffer R. Beyond here be dragons: SIBO in Parkinson's disease. Mov Disord. 2013;28(13):1764-5.

[216] Scheperjans F, Aho V, Pereira PA, Koskinen K, Paulin L, Pekkonen E, Haapaniemi E, Kaakkola S, Eerola-Rautio J, Pohja M, Kinnunen E, Murros K, Auvinen P. Gut microbiota are related to Parkinson's disease and clinical phenotype. Mov Disord. 2015;30(3):350-8. 
[217] Unger MM, Spiegel J, Dillmann KU, Grundmann D, Philippeit H, Bürmann J, Faßbender K, Schwiertz A, Schäfer KH. Short chain fatty acids and gut microbiota differ between patients with Parkinson's disease and agematched controls. Parkinsonism Relat Disord. 2016;32: 66-72.

[218] Zhang F, Yue L, Fang X, Wang G, Li C, Sun X, Jia X, Yang J, Song J, Zhang Y, Guo C, Ma G, Sang M, Chen F, Wang P. Altered gut microbiota in Parkinson's disease patients/healthy spouses and its association with clinical features. Parkinsonism Relat Disord. 2020;81: 84-88.

[219] Sun MF, Zhu YL, Zhou ZL, Jia XB, Xu YD, Yang Q, Cui C, Shen YQ. Neuroprotective effects of fecal microbiota transplantation on MPTP-induced Parkinson's disease mice: Gut microbiota, glial reaction and TLR4/TNF- $\alpha$ signaling pathway. Brain Behav Immun. 2018;70:48-60.

[220] Fatma KOC, Susan Mills, Conall Strain, R.Paul Ross and Catherine Stanton (2020). The public health rationale for increasing dietary fibre: Health benefits with a focus on gut microbiota, Nutrition Bulletin, British Nutrition Foundation. DOI: 10.1111/nbu.12448hi.

[221] Berding K, Carbia C, Cryan JF. Going with the grain: Fiber, cognition, and the microbiota-gut-brain-axis. Exp Biol Med (Maywood). 2021;246(7):796-811.

[222] Berding K, Long-Smith CM, Carbia C, Bastiaanssen TFS, van de Wouw M, Wiley N, Strain CR, Fouhy F, Stanton C, Cryan JF, Dinan TG. A specific dietary fibre supplementation improves cognitive performance-an exploratory randomised, placebo-controlled, crossover study. Psychopharmacology (Berl). 2021;238(1):149-63.

[223] Gibson GR, Hutkins R, Sanders ME, Prescott SL, Reimer RA, Salminen SJ, Scott K, Stanton C, Swanson KS, Cani PD, Verbeke K, Reid G. Expert consensus document: The International Scientific Association for Probiotics and Prebiotics (ISAPP) consensus statement on the definition and scope of prebiotics. Nat Rev Gastroenterol Hepatol. 2017;14(8):491-502.

[224] Food and Agricultural Organization of the United Nations and World Health Organization. Health and nutritional properties of probiotics in food including powder milk with live lactic acid bacteria. World Health Organization [online], http://www.who.int/foodsafety/publications/ fs_management/en/probiotics.pdf (2001).

[225] Salminen S, Collado MC, Endo A, Hill C, Lebeer S, Quigley EMM, Sanders ME, Shamir R, Swann JR, Szajewska H, Vinderola G. The International Scientific Association of Probiotics and Prebiotics (ISAPP) consensus statement on the definition and scope of postbiotics. Nature Reviews Gastroenterology \& Hepatology. 2021;18:649-7.

[226] Salazar N, Valdés-Varela L, González S, Gueimonde M, de Los Reyes-Gavilán CG. Nutrition and the gut microbiome in the elderly. Gut Microbes. 2017;8(2):82-97.

[227] Pray LA. Institute of Medicine (US); Planning Committee for Food Supply and Aging Populations, National Academies Press (US). Providing Healthy and Safe Foods as We Age: Workshop Summary; National Academies Press: Washington, DC, USA, 2010.

[228] Cuervo A, Salazar N, Ruas-Madiedo P, Gueimonde M, González S. Fiber from a regular diet is directly associated with fecal short-chain fatty acid concentrations in the elderly. Nutr Res. 2013;33(10):811-6.
[229] Mills S, Lane JA, Smith GJ, Grimaldi KA, Ross RP, Stanton C. Precision Nutrition and the Microbiome Part II: Potential Opportunities and Pathways to Commercialisation. Nutrients. 2019b;11(7):1468.

[230] Vulevic J, Juric A, Walton GE, Claus SP, Tzortzis G, Toward $\mathrm{RE}$, Gibson GR. Influence of galacto-oligosaccharide mixture (B-GOS) on gut microbiota, immune parameters and metabonomics in elderly persons. $\mathrm{Br} \mathrm{J}$ Nutr. 2015;114(4):586-95.

[231] Walton GE, van den Heuvel EG, Kosters MH, Rastall RA, Tuohy KM, Gibson GR. A randomised crossover study investigating the effects of galacto-oligosaccharides on the faecal microbiota in men and women over 50 years of age. Br J Nutr. 2012;107(10):1466-75.

[232] Bouhnik Y, Achour L, Paineau D, Riottot M, Attar A, Bornet F. Four-week short chain fructo-oligosaccharides ingestion leads to increasing fecal bifidobacteria and cholesterol excretion in healthy elderly volunteers. Nutr J. 2007;6:42.

[233] Buigues C, Fernández-Garrido J, Pruimboom L, Hoogland AJ, Navarro-Martínez R, Martínez-Martínez M, Verdejo Y, Mascarós MC, Peris C, Cauli O. Effect of a Prebiotic Formulation on Frailty Syndrome: A Randomized, Double-Blind Clinical Trial. Int J Mol Sci. 2016; 17(6):932.

[234] Theou O, Jayanama K, Fernández-Garrido J, Buigues C, Pruimboom L, Hoogland AJ, Navarro-Martínez R, Rockwood K, Cauli O. Can a Prebiotic Formulation Reduce Frailty Levels in Older People? J Frailty Aging. 2019;8(1):48-52.

[235] Gill HS, Rutherfurd KJ, Cross ML, Gopal PK. Enhancement of immunity in the elderly by dietary supplementation with the probiotic Bifidobacterium lactis HN019. Am J Clin Nutr. 2001;74(6):833-9.

[236] Spaiser SJ, Culpepper T, Nieves C, Jr., Ukhanova M, Mai V, Percival SS, Christman MC, Langkamp-Henken B. Lactobacillus gasseri KS-13, Bifidobacterium bifidum G9-1, and Bifidobacterium longum MM-2 Ingestion Induces a Less Inflammatory Cytokine Profile and a Potentially Beneficial Shift in Gut Microbiota in Older Adults: A Randomized, Double-Blind, Placebo-Controlled, Crossover Study. J Am Coll Nutr. 2015;34(6):459-69.

[237] Lahtinen SJ, Forssten S, Aakko J, Granlund L, Rautonen N, Salminen S, Viitanen M, Ouwehand AC. Probiotic cheese containing Lactobacillus rhamnosus HN001 and Lactobacillus acidophilus NCFM ${ }^{\circledR}$ modifies subpopulations of fecal lactobacilli and Clostridium difficile in the elderly. Age (Dordr). 2012;34(1):133-43.

[238] Allen SJ, Wareham K, Wang D, Bradley C, Sewell B, Hutchings H, Harris W, Dhar A, Brown H, Foden A, Gravenor MB, Mack D, Phillips CJ. A high-dose preparation of lactobacilli and bifidobacteria in the prevention of antibiotic-associated and Clostridium difficile diarrhoea in older people admitted to hospital: a multicentre, randomised, double-blind, placebo-controlled, parallel arm trial (PLACIDE). Health Technol Assess. 2013;17(57): 1-140.

[239] Nagamine T, Matsumoto Y, Nakamura M. Combination probiotics may prevent Clostridium difficile infection among elderly patients undergoing an orthopedic surgery. Biosci Microbiota Food Health. 2019;38(1): 31-3. 
[240] Rampelli S, Candela M, Severgnini M, Biagi E, Turroni S, Roselli M, Carnevali P, Donini L, Brigidi P. A probiotics-containing biscuit modulates the intestinal microbiota in the elderly. J Nutr Health Aging. 2013b;17(2): 166-72.

[241] Xiao J, Katsumata N, Bernier F, Ohno K, Yamauchi Y, Odamaki T, Yoshikawa K, Ito K, Kaneko T. Probiotic Bifdobacterium breve in Improving Cognitive Functions of Older Adults with Suspected Mild Cognitive Impairment: A Randomized, Double-Blind, Placebo-Controlled Trial. J Alzheimers Dis. 2020;77(1):139-47.
[242] Barichella M, Pacchetti C, Bolliri C, Cassani E, Iorio L, Pusani C, Pinelli G, Privitera G, Cesari I, Faierman SA, Caccialanza R, Pezzoli G, Cereda E. Probiotics and prebiotic fiber for constipation associated with Parkinson disease: An RCT. Neurology. 2016;87(12):1274-80.

[243] Ibrahim A, Ali RAR, Manaf MRA, Ahmad N, Tajurruddin FW, Qin WZ, Desa SHM, Ibrahim NM. Multi-strain probiotics (Hexbio) containing MCP BCMC strains improved constipation and gut motility in Parkinson's disease: A randomised controlled trial. PLoS One. 2020;15(12): $\mathrm{e} 0244680$. 